AperTO - Archivio Istituzionale Open Access dell'Università di Torino

\title{
PM10 size distribution of metals and environmental-sanitary risk analysis in the city of Torino
}

\section{This is the author's manuscript}

Original Citation:

Availability:

This version is available http://hdl.handle.net/2318/154029

since 2016-02-04T09:57:19Z

Published version:

DOI:10.1016/j.chemosphere.2014.04.034

Terms of use:

Open Access

Anyone can freely access the full text of works made available as "Open Access". Works made available under a Creative Commons license can be used according to the terms and conditions of said license. Use of all other works requires consent of the right holder (author or publisher) if not exempted from copyright protection by the applicable law. 


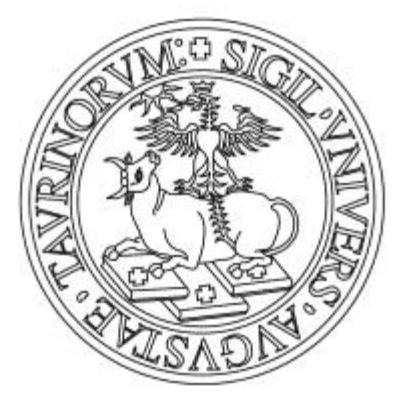

\section{UNIVERSITÀ DEGLI STUDI DI TORINO}

This Accepted Author Manuscript (AAM) is copyrighted and published by Elsevier. It is posted here by agreement between Elsevier and the University of Turin. Changes resulting from the publishing process - such as editing, corrections, structural formatting, and other quality control mechanisms - may not be reflected in this version of the text. The definitive version of the text was subsequently published in:

[Chemosphere , 112, October, 2014, DOI: 10.1016/j.chemosphere.2014.04.034]

You may download, copy and otherwise use the AAM for non-commercial purposes provided that your license is limited by the following restrictions:

(1) You may use this AAM for non-commercial purposes only under the terms of the CC-BY-NCND license.

(2) The integrity of the work and identification of the author, copyright owner, and publisher must be preserved in any copy.

(3) You must attribute this AAM in the following format: Creative Commons BY-NC-ND license (http://creativecommons.org/licenses/by-nc-nd/4.0/deed.en), [+ Digital Object Identifier link to the published journal article on Elsevier's ScienceDirect ${ }^{\circledR}$ platform] 


\section{Elsevier Editorial System(tm) for Chemosphere Manuscript Draft}

Manuscript Number: CHEM31198R1

Title: PM10 size distribution of metals and environmental-sanitary risk analysis in the city of Torino

Article Type: Research Paper

Section/Category: Environmental Toxicology and Risk Assessment

Keywords: PM10; metals; health-sanitary risk analysis

Corresponding Author: Dr. Tiziana Schilirò,

Corresponding Author's Institution: University of Torino

First Author: Valeria Romanazzi, phD

Order of Authors: Valeria Romanazzi, phD; Marco Casazza; Mery Malandrino; Valter Maurino; Angelo Piano; Tiziana Schilirò; Giorgio Gilli

Response to Reviewers: REVIEWER COMMENTS

Reviewer \#1:

Review of the manuscript CHEM31198 entitled "PM10 size distribution of metals and environmentalsanitary risk analysis in the city of Torino". In this paper the authors investigated the metal distribution in different fraction of PM samples collected in a north Italian city (Torino) evaluating the risk associated to airborne PM10 metals by quantitative risk assessment (QRA). The subject of the paper is interesting, in particular considering that there are few works that associate the PM metal distribution in different fraction to health effects using QRA.

It is not within my competence but English grammar should be correct all over the manuscript.

The work is well organized but some considerations about the manuscript are reported below:

Page 3 line 55 better clarify the second bullet point

Page 3 line 56 add "some" after "risk for"

Page 3 line 59 delete "Particulate Matter" or "PM10" and add another key word

Page 4 line 95 add other references (e.g. Bonetta et al., 2009)

Page 5 line 121-125 some repetition appears in the, please read better and rewrite

Page 6 line 131 add some example of fields of interest

Page 6 line 142 delete "only"

Page 6 line 152 check the word "weighing"

Page 7 line 158 delete the word "starting"

Page 7 line 161 detail the technique used (ICP? or others?)

Page 7 line 171 detail the different PM fraction considered

Page 7 line 174 explain why only inhalation route was considered

Page 7 line 177 add after "calculated" the sentence "...,where possible,..."

Page 8 line 182-183 moves this sentence after "...to be without effect.." page 7 line 181 and add the corresponding equation 
Page 8 line 191 explain better "one field"

Page 8 line 192 add "...,where possible,..." after "for each contaminant"

Page 8 line 193-195 better explain adding the corresponding equation

Page 8 line 202-204 moves the sentence after "for each contaminant" line 192

Page 8 line 204 check the word ingestion and change with inhalation

Page 8 line 205-207 add some references

Page 9 line 210 detail better the different fraction investigated (eight and three)

Page 9 line 220 add "Italian regulation" after "set by"

Page 9 line 230 add "Italian regulation" after "set by"

Page 9 line 230-231 check the sentence

Page 10 line 242 add (Table 3 ) at the end of the sentence

Page 10 line 247 moves "Figure 1" after "fine PM1" line 244

Page 10 line 247 explain and detail the trend of metal distribution in the different fraction

Page 10 line 257 add the range of risk revealed

Page 11 line 260 check this sentence because a clear differences between adult and child is not showed in the figure

Page 11 line 262-263 moves this sentence after "Cd" line 263

Page 11 line 271 add the value of risk calculated

Page 11 line 282 add "using QRA"

Page 12 line 290-300 this period is too long

Page 12 line 301 add "toxic or" after "potential"

Page 13 line add consideration regarding the risk associated to the metal presence in the different fractions

Table 1 add reference

Table 2 change ISPLES with ISPESL and SF with CSF

Table 3 change "expressed as ng/m3" with "expressed as mean ng/m3" and moves the sentence "in particular....textured filter" in the results section.

\section{Reviewer \#2:}

The manuscript "PM10 size distribution of metals and environmental-1 sanitary risk analysis in the city of Torino" by Romanazzi et al. aims to evaluate the levels and distribution of 16 particulate-bound metals and to assess the respective non-carcinogenic and carcinogenic risks.

The manuscript is clearly written. The number of figures and tables are adequate and well organized. The used techniques are satisfactory but detailed description concerning the analytical process is missing. Although the obtained results might be interesting to readers of Chemosphere I have two major comments:

1. This manuscript reports findings based on 3-day PM sampling at 1 site. Although 7-stage impactor was used (i.e. total of 24 samples) this seems as rather limited set of data /short period. Furthermore, the obtained levels of PM metals are then compared with annual target values. I have doubts about relevance of this information in view of 3-day sample collection during 1 season at one site only. In addition for international readers it will be interesting to compare obtained levels of metals (and the respective risks) with European or USEPA guidelines rather than Italian national limits/risks guidelines.

2. Authors estimated risks due to exposure to particulate-bounds metals, i.e. inhalation exposure by USEPA methodology. However, their calculations are performed using values for ingestions (i.e. oral exposure). I strongly advice authors to revise (and to correct) their approach. In the comments below I attach the link for respective USEPA methodology. In addition, the selection of some critical 
parameters (body weight, inhalation rates, period of daily outdoor exposure) needs clarification/justification. For that authors should consult the respective USEPA reports (please see in specific comments). The discussion should also include more detailed information/comparisons of risks of both age categories (children versus adults)

Further comments are listed in the section below which I hope to improve author their work

\section{INTRODUCTION}

Line 117-120: Information concerning EU legislation on carcinogenic metals (As, $\mathrm{Cd}, \mathrm{Ni}$ ) in ambient air should be completed: indicated targets are annual ones and determined in PM10.

Line 121-132: rephrase this section and clearly state the objectives of this work. Why information about "historical evolution of size fractioned PM10 evolution of the ". Is it relevant to this work? Please clarify/rephrase

Line 128-131: Information about importance of risk assessment should be placed in the previously in introduction and not in the objectives.

Please correct references within whole manuscript once space appears before comma ( "al. ,")

\section{MATERIALS AND METHODS}

Section 2.1:

Sampling site and its characteristic should be better described: define site (urban, background) and it major influences (traffic, industrial, etc.). What were the surroundings of sampling site?

Section 2.2:

Information on quality control/assurance of analytical process should be introduced. LODs/LOQs are missing too.

Section 2.3:

1. The non-carcinogenic and carcinogenic risks to particulate trace elements were calculated according to the USEPA methodology. Information concerning USEPA risk guidelines should be therefore included (THQ less than 1; for CR considers risk range 10-6 to 10-4: values below 10-6 for individual chemicals and pathways will cause negligible cancer risks but caution is recommended to ensure that the cumulative cancer risk for all potential carcinogenic contaminants does not have a residual cancer risk exceeding $10-4$ ).

2. Authors should justify the selected values for the following parameters in Table 1: BW, IR, Bo. For example inhalation rate of $0.9 \mathrm{~L} / \mathrm{min}$ correspond to what level of physical activity? Please see USEPA materials concerning the respective information for adult and children, respectively:

USEPA Exposure Factors Handbook: http://www.epa.gov/ncea/efh/pdfs/efh-complete.pdf Child-Specific Exposure Factors Handbook:

http://cfpub.epa.gov/ncea/cfm/recordisplay.cfm?deid=199243

In addition, $\mathrm{EFg}$ of $6 \mathrm{~h} /$ day (25\%) for outdoor exposure seems rather high once people spend indoors typically $80-95 \%$. Once again authors should justify/correct the selected value.

3. Finally, authors estimate risks due to exposure to metals in PM10 in ambient air. Assumingly these are inhalation risks but the THQ and CR calculation were done using reference dose (RfD) and cancer slope (CSF) for ingestion exposure. It is not clear to me why authors did not use the USEPA methodology for inhalation exposure (Chronic Inhalation Reference Concentration RfC $(\mathrm{mg} / \mathrm{m} 3)$; Chronic Inhalation Unit Risk IUR ( $\mu \mathrm{g} / \mathrm{m} 3)-1$ (THQ, TR). The available information can be found here: (section 4.9.1-2): http://www.epa.gov/reg3hwmd/risk/human/rb-

concentration_table/usersguide.htm

I think that their approach needs major revisions.

4. Table 2: Reference [17]? Missing in the list of references (ISS-ISPESL).It is difficukt to find/confirm data in Italian database. Furthermore, once USEPA approach is used, RfD and CSF referred by USEPA should be use: please consult the following link for Regional Screening Level (RSL) Summary Table: http://www.epa.gov/reg3hwmd/risk/human/rb-

concentration_table/Generic_Tables/docs/master_sl_table_run_NOV2013.pdf 


\section{RESULT}

Lines 222-233 (section 3.1) should be enhanced: authors compared average metals concentrations of 3 days measurements with annual targets. In addition, according to the statement in lines 140-142 the measurements were performed during winter season with greater exposure i.e. metals levels in ambient air; the EU target values might not be exceeded during other seasons.

Lines 264-265 This statement is obvious once PM10 contains both fractions. Remove/change. Lines 265-266: Considering different deposition places of both fractions the statement "indeed total PM10......" is not correct. I am not sure what authors want to state. Furthermore according to Figure 1 most of the some metals (are predominantly (up to 70\%) found in fine fraction.

DISCUSSION

Line 288-300 this section should be placed in introduction Line 301: Mn causes carcinogenic risks.... CR risk assessment of Mn was not performed.

Authors should add discussion on different species metals and potential impacts. Finally, I believe that changes in calculations of THQ, CR using IUR, RfC will cause major changes/alterations which should be reflected in results/discussion.

\section{RESPONSE TO REVIEWERS COMMENTS}

Response to Reviewer \#1 comments:

We thank the reviewer for the suggested amendments.

All specific corrections have been answered and are highlighted in yellow in the revised manuscript.

We clarified the second bullet point.

We added, deleted, clarified and rewrote all the reviewer \#1 suggested.

We added some example of fields of interest at lines 135-137.

The technique utilized was "inductively coupled plasma - mass spectrometer". It is now specified in the main text; globally more details concerning this method were provide (lines 170-185).

We detailed the different PM fraction considered (already reported in Section 2.1) in the main text. A sentence was added and highlighted in the main text (lines 195-196) to explain why only inhalation route was considered.

We changed ingestion with inhalation all over the text, it was an authors mistake.

We substituted the Italian reference about legislation with the European Directive one (2008/50/EC) all over the manuscript.

We added two descriptive sentences at lines 297-299 and 302-303 to explain and detail the trend of metal distribution in the different fraction

We add the THQ and CR ranges modifying the sentences at lines 311-317 adding the range of risk revealed

The little CR difference between adult and child was not clear as suggested by the reviewer\#1 in figure 3 because of the log scale, but adding the ranges in the previous sentence it is explained.

For Cd we add the THQ and CR ranges at lines 329-330.

Done, as required, at line 342 , but we use " by means of environmental-sanitary risk assessment" in order to be consistent.

We added consideration regarding the risk associated to the metal presence in the different fractions at lines 345-348.

In Table 2 (past Table 1) we added references: USEPA 1991, USEPA 2009 and USEPA 2011. 
In Table 1 (past Table 2) we changed reference with one updated from USEPA (USEPA November 2013). New calculations were performed according with these new values.

In Table 3 we change what the reviewer suggested.

Response to Reviewer \#2 comments:

We thank the reviewer for the suggested amendments.

All specific corrections have been answered and are highlighted in yellow in the revised manuscript).

Major Comments :

1.

Concerning the European guidelines, the D.Lgs 155, 2010 mentioned as reference represents the Italian transposition of the European Directive 2008/50/EC: we have replaced the Italian transposition with the European Directive along all the manuscript, in order to provide to international readers greater opportunity for comparison.

Concerning the 3-day PM sampling at one site, actually the sampling occurred during three autumn/winter days and this choice is due to different factors: - during this period the emission sources of atmospheric pollutants are more numerous and intense; -in the same period some atmospheric phenomena occur, such as thermal inversions, that can lead to a greater exposure levels for the population. These two factors are very important because in view of a risk analysis we looked the worst pollution conditions under the principle of maximum precaution.

Concerning the comparison with metals annual target values, we are aware of the discrepancy but it was only to provide the readers with a comparison, for this reason we underlined this at lines 276-277.

2.

About inhalation and ingestion routes, it was a spelling mistake. Ingestion clearly was not adequate, the used approach and values were referred to inhalation: we have corrected all over the main text (Also the other reviewer underlined the mistake!).

The methodology procedure for the estimation of inhalation exposure was detailed in USEPA 1989, USEPA 2009 -Part F and in USEPA 2011 and new details concerning the risk analysis calculation were added in Material and Methods Section (lines 231-250), according with USEPA Method. Default parameters used in the calculations of risk analysis are now detailed in Table 2. Further argumentation about your comment are present in Materials \& Methods - Section 2.3.

About the comparisons of risks of both children and adults we highlighted this aspect at lines 312-317 and in the abstract at lies 37-38; we also add this consideration at lines 368-372.

Further comments:

INTRODUCTION

Information concerning EU legislation on carcinogenic metals (As, $\mathrm{Cd}, \mathrm{Ni}$ ) in ambient air were added at lines 128-130.

We rephrased the section and clearly stated the objectives of the work. In particular the historical evaluation based on a previous study on the same area (Casazza 2013) is fundamental since the change in the emission sources examined in that occasion is related to a different deposition of metals (and other pollutants not here investigated) on different fractions of PM10 (lines 138-143).

We added a brief comment about the importance of risk assessment in the introduction (lines 133137). 
The references has been revised for editing.

\section{MATERIALS AND METHODS}

Section 2.1:

Sampling site and its characteristic are highlighted at lines 162-164.

Section 2.2:

Details concerning quality control and LOD/LOQ were added and highlighted in the Materials and Methods Section (lines 188-191).

Section 2.3:

1.

Information concerning non-carcinogenic and carcinogenic risks guidelines are highlighted at lines 210-214 and lines 221-229 respectively.

2.

Simplified information were embedded in the caption of Table 1, now named Table 2; the table now receive the English acronyms of singular parameters, as well as the correct references (USEPA 1991, USEPA 2009 - Part F and USEPA 2011). The inhalation rates (IR) were $0,9 \mathrm{~m} 3 / \mathrm{h}$ for adult and $0,7 \mathrm{~m} 3 / \mathrm{h}$ for children considering male and female combined for sedentary and light activity (USEPA 2011). From "Standard Default Exposure Factors" (USEPA 1991) and from USEPA 2009 Part F, Exposure Frequency (EF), Exposure Duration (ED) and Body Weight (BW) parameters were inferred, taking into account the "Inhalation of contaminant" as exposure pathway in a "residential scenario". An example of a residential scenario could consist of inhalation exposure for up to 24 hours per day, up to 350 days per year for 6 to 24 years for child and adult respectively (USEPA 2009 - Part F).

The methodology procedure for the estimation of inhalation exposure was detailed in USEPA 2009 Part F Document.

Concerning the exposure parameters related to EFg value (now daily Exposure Time= ET), the USEPA 1991 Document indicates " 24 hours, the whole day" as "resident air exposure time" and then setting in according with time spent in a specific site. Actually, in the light of your suggestions, an ED value of 6 hours seems rather high, thus as recommended by USEPA table of time spent outdoor (mean of 289 min/day for maximum age range considered) and according with lower limit indicated by you (8095\% time spent indoor), we have correct it considering 5 hours as ED value. Calculation were again performed.

3.

About inhalation and ingestion routes, it was a spelling mistake (your comment $n^{\circ} 2$ )

In the light of the suggestions, we have checked the USEPA methodology and new calculations were performed, taking into account the most recent USEPA update (November 2013) concerning RfC and IUR values, as added in the manuscript (page 9, lines 231-242).

4.

"Table 2" is now entitled "Table 1"; here the updated values from USEPA 2013 updated Table were reported as you suggested, and new specifications about it were provided in the text in the Material and Methods Section.

RESULT

section 3.1

We added a sentence at lines 276-277 to better explain the considerations about PM and metals concentration .

We removed the sentence about the PM10 inhalation and we improved the text at lines 300-303 as suggested.

DISCUSSION 
We moved the indicated sentence in the introduction (lines 111-117).

About Mn it was a mistake so we added toxic referred to Mn (lines 349-350). We also discussed about different species metals and potential impacts (lines 350-362). 


\section{UNIVERSITY OF TORINO, ITALY}

Department of Public Health and Pediatrics

Hygiene Division - Via Santena 5 bis

10126 TORINO, Italy

December $13^{\text {th }}, 2013$

Dear Editor,

We are sending the manuscript "PM10 size distribution of metals and environmental-sanitary risk analysis in the city of Torino" by Valeria Romanazzi, Marco Casazza, Mery Malandrino, Valter Maurino, Angelo Piano, Tiziana Schilirò*, Giorgio Gilli for possible publication on Chemosphere.

Referring to the biomonitoring of chemicals related to adverse health effects, the current study is aimed to calculate the environmental-sanitary risk linked to exposure to airborne PM10 metals. Metals PM10 size distribution analysis was carried out in a central site of Torino city-Italy. While the concentrations of all the sampled metals appeared to be under control, their presence in the different PM10 fractions and their sanitary risk provided indications related to the body districts potentially in contact with these substances.

The manuscript has been seen and approved by all co-authors. I confirm that neither the manuscript nor any part of it has been published or is under consideration for publication elsewhere.

Lastly, all authors declare no conflicting interests.

Hoping that the manuscript may fulfil the scientific standards of Chemosphere, my best regards.

Dr. Tiziana Schilirò

Contacts:

Phone: (+39) 0116705810

Fax: (+39) 0116705874

e-mail: tiziana.schiliro@unito.it 


\section{HIGHLIGHTS:}

- $\quad$ Traces metals are differently distributed among the PM10 fractions

- $\quad$ The metals distribution in PM fractions can be useful for sanitary risk assessment

- Sanitary risk assessment shows potential risks for exposure to some metals on PM 
Dear Editor,

please find enclosed the revised manuscript "PM10 size distribution of metals and environmentalsanitary risk analysis in the city of Torino" - CHEM31198 - by Valeria Romanazzi, Marco Casazza, Mery Malandrino, Valter Maurino, Angelo Piano, Tiziana Schilirò* and Giorgio Gilli.

We have answered to all the Reviewers' comments, in particular relevant changes have been highlighted in yellow all over the enclosed text. Finally, our comments to Reviewers have been reported as follows.

Best regards,

Tiziana Schilirò and Co-authors.

\section{Reviewer \#1}

We thank the reviewer for the suggested amendments. All specific corrections have been answered and are listed in the original reviewer text below.

- "It is not within my competence but English grammar should be correct all over the manuscript"

The manuscript was carefully revised and corrected by a English native speaker and now it appears in a better grammatical form.

Other comments:

- Page 3 line 55 better clarify the second bullet point

Ok, we clarified the second bullet point

- Page 3 line 56 add "some" after "risk for"

Done, as you required.

- Page 3 line 59 delete "Particulate Matter" or "PM10" and add another key word Done, as you required.

- Page 4 line 95 add other references (e.g. Bonetta et al., 2009)

Done, as you required.

- Page 5 line 121-125 some repetition appears in the, please read better and rewrite Done. In particular a repeated sentence was deleted

- Page 6 line 131 add some example of fields of interest

Done; the added specifications were at lines 135-137.

- Page 6 line 142 delete "only"

Done, as you required. 
- Page 6 line 152 check the word "weighing"

We have checked it, but appears right (= to weigh the filters)

- Page 7 line 158 delete the word "starting"

Done, as you required.

- Page 7 line 161 detail the technique used (ICP? or others ?)

Yes, the technique is "inductively coupled plasma - mass spectrometer". It is now specified in the main text; globally more details concerning this method were provide, as you can see in the highlighted text (lines 170-185).

- Page 7 line 171 detail the different PM fraction considered

Done. Details (already reported in Section 2.1) were added and highlighted in the main text

- Page 7 line 174 explain why only inhalation route was considered

Done. A sentence was added and highlighted in the main text (lines 195-196).

- Page 7 line 177 add after "calculated" the sentence "..., where possible,..."

Done, we add it at pag. 9 line 232.

- Page 8 line 182-183 moves this sentence after "...to be without effect.." page 7 line 181 and add the corresponding equation

Done, as you required.

- Page 8 line 191 explain better "one field"

Done, as you required.

- Page 8 line 192 add "..., where possible,..." after "for each contaminant" Done, we add it at pag. 9 line 232.

- Page 8 line 193-195 better explain adding the corresponding equation Done, as you required at line 245 .

- Page 8 line 202-204 moves the sentence after "for each contaminant" line 192 Done, as you required.

- Page 8 line 204 check the word ingestion and change with inhalation Done, as you required, thank you it was inhalation.

- Page 8 line 205-207 add some references Done, as you required.

- Page 9 line 210 detail better the different fraction investigated (eight and three) Done, as you required.

- Page 9 line 220 add "Italian regulation" after "set by"

- Page 9 line 230 add "Italian regulation" after "set by" 
Done, as you required, but we add for the reference European Directive 2008/50/EC all over the manuscript.

- Page 9 line 230-231 check the sentence We have improved the sentence.

- Page 10 line 242 add (Table 3) at the end of the sentence At line 247 "Table 3" it was already present.

- Page 10 line 247 moves "Figure 1" after "fine PM1" line 244 Done, as you required.

- Page 10 line 247 explain and detail the trend of metal distribution in the different fraction Done, as you required, we add two descriptive sentences at lines 297-299 and 302-303.

- Page 10 line 257 add the range of risk revealed Done, as you required, we add the THQ and CR ranges modifying the sentences at lines 311-317.

- Page 11 line 260 check this sentence because a clear differences between adult and child is not showed in the figure.

Done, as you required: really the little CR difference between adult and child is not clear in figure 3 because of the log scale, but adding the ranges in the previous sentence it is explained.

- Page 11 line 262-263 moves this sentence after "Cd" line 263 Thank you for the observation, we clarified the sentence.

- Page 11 line 271 add the value of risk calculated Done, as you required at lines 329-330.

- Page 11 line 282 add "using QRA" Done, as required, at line 342 , but we use " by means of environmental-sanitary risk assessment" in order to be consistent.

- Page 12 line 290-300 this period is too long Done, we modified the sentences.

- Page 12 line 301 add "toxic or" after "potential" Done, as required.

- Page 13 line add consideration regarding the risk associated to the metal presence in the different fractions We highlighted these considerations at lines 345-348.

- Table 1 add reference Now Table 2; done, we added USEPA 1991, USEPA 2009 and USEPA 2011 as references.

- Table 2 change ISPLES with ISPESL and SF with CSF 
Now Table 1. Done, we changed that reference with one updated from USEPA (USEPA November 2013). New calculations were performed according with these new values.

- Table 3 change "expressed as ng/m3" with "expressed as mean ng/m3" and moves the sentence "in particular....textured filter" in the results section.

Done as required.

\section{Reviewer \#2}

We thank the reviewer for the suggested amendments. All specific corrections have been answered and are listed in the original reviewer text below.

Major Comments :

- "1- This manuscript reports findings based on 3-day PM sampling at 1 site. Although 7- stage impactor was used (i.e. total of 24 samples) this seems as rather limited set of data /short period. Furthermore, the obtained levels of PM metals are then compared with annual target values. I have doubts about relevance of this information in view of 3-day sample collection during 1 season at one site only. In addition for international readers it will be interesting to compare obtained levels of metals (and the respective risks) with European or USEPA guidelines rather than Italian national limits/risks guidelines".

Concerning the European guidelines, the D.Lgs 155, 2010 mentioned as reference represents the Italian transposition of the European Directive 2008/50/EC: we have replaced the Italian transposition with the European Directive along all the manuscript, in order to provide to international readers greater opportunity for comparison.

Concerning the 3-day PM sampling at one site, actually the sampling occurred during three autumn/winter days and this choice is due to different factors: - during this period the emission sources of atmospheric pollutants are more numerous and intense; -in the same period some atmospheric phenomena occur, such as thermal inversions, that can lead to a greater exposure levels for the population. These two factors are very important because in view of a risk analysis we looked the worst pollution conditions under the principle of maximum precaution.

Concerning the comparison with metals annual target values, we are aware of the discrepancy but it was only to provide the readers with a comparison, for this reason we underlined this at lines 276-277.

- "2- Authors estimated risks due to exposure to particulate-bounds metals, i.e. inhalation exposure by USEPA methodology. However, their calculations are performed using values for ingestions (i.e. oral exposure). I strongly advice authors to revise (and to correct) their approach. In the comments below I attach the link for respective USEPA methodology. In addition, the selection of some critical parameters 
(body weight, inhalation rates, period of daily outdoor exposure) needs clarification/justification. For that authors should consult the respective USEPA reports (please see in specific comments). The discussion should also include more detailed information/comparisons of risks of both age categories (children versus adults)".

Thank you for the observation. It was a spelling mistake. Ingestion clearly was not adequate, the used approach and values were referred to inhalation: we have corrected all over the main text (Also the other reviewer underlined the mistake!).

The methodology procedure for the estimation of inhalation exposure was detailed in USEPA 1989, USEPA 2009 -Part F and in USEPA 2011 and new details concerning the risk analysis calculation were added in Material and Methods Section (lines 231-250), according with USEPA Method. Default parameters used in the calculations of risk analysis are now detailed in Table 2. Further argumentation about your comment are present in Materials \& Methods - Section 2.3.

About the comparisons of risks of both children and adults we highlighted this aspect at lines 312-317 and in the abstract at lies 37-38; we also add this consideration at lines 368-372.

Further comments:

\section{INTRODUCTION}

- Line 117-120: Information concerning EU legislation on carcinogenic metals (As, Cd, Ni) in ambient air should be completed: indicated targets are annual ones and determined in PM10.

Done, as you required. The added part is highlighted at lines 128-130.

- Line 121-132: rephrase this section and clearly state the objectives of this work. Why information about "historical evolution of size fractioned PM10 evolution of the ". Is it relevant to this work? Please clarify/rephrase.

Done. In particular a repeated statement was deleted. As yet affirmed in the manuscript, the historical evaluation based on a previous study on the same area (Casazza 2013) is fundamental since the change in the emission sources examined in that occasion is related to a different deposition of metals (and other pollutants not here investigated) on different fractions of PM10 (lines 138-143).

- Line 128-131: Information about importance of risk assessment should be placed in the previously in introduction and not in the objectives. Please correct references within whole manuscript once space appears before comma ("al. ,").

Yes, we have added a brief comment about it, and is highlighted at lines 133-137. Also the references has been revised, taking into account your observation. 


\section{MATERIALS AND METHODS}

Section 2.1:

Sampling site and its characteristic should be better described: define site (urban, background) and it major influences (traffic, industrial, etc.). What were the surroundings of sampling site?

Ok, sampling site and its characteristic are highlighted at lines 162-164.

- Section 2.2:

Information on quality control/assurance of analytical process should be introduced. LODs/LOQs are missing too.

Thank you, now details concerning quality control and LOD/LOQ were added and highlighted in the Materials and Methods Section, as you required (lines 188-191).

- Section 2.3:

1. The non-carcinogenic and carcinogenic risks to particulate trace elements were calculated according to the USEPA methodology. Information concerning USEPA risk guidelines should be therefore included (THQ less than 1; for CR considers risk range 10-6 to 10-4: values below 10-6 for individual chemicals and pathways will cause negligible cancer risks but caution is recommended to ensure that the cumulative cancer risk for all potential carcinogenic contaminants does not have a residual cancer risk exceeding $10-4)$.

Information concerning non-carcinogenic and carcinogenic risks guidelines are highlighted at lines 210 214 and lines 221-229 respectively.

- 2. Authors should justify the selected values for the following parameters in Table 1: BW, IR, Bo. For example inhalation rate of $0.9 \mathrm{~L} / \mathrm{min}$ correspond to what level of physical activity? Please see USEPA materials concerning the respective information for adult and children, respectively:

USEPA Exposure Factors Handbook: http://www.epa.gov/ncea/efh/pdfs/efh-complete.pdf ChildSpecific Exposure Factors Handbook: http://cfpub.epa.gov/ncea/cfm/recordisplay.cfm?deid=199243 In addition, EFg of 6h/day (25\%) for outdoor exposure seems rather high once people spend indoors typically 80-95\%. Once again authors should justify/correct the selected value.

Thank you for your observation. Simplified information were embedded in the caption of Table 1, now named Table 2; the table now receive the English acronyms of singular parameters, as well as the correct references (USEPA 1991, USEPA 2009 - Part F and USEPA 2011). The inhalation rates (IR) were $0,9 \mathrm{~m}^{3} / \mathrm{h}$ for adult and $0,7 \mathrm{~m}^{3} / \mathrm{h}$ for children considering male and female combined for sedentary and light activity (USEPA 2011). From "Standard Default Exposure Factors" (USEPA 1991) and from USEPA 2009 Part F, Exposure Frequency (EF), Exposure Duration (ED) and Body Weight (BW) parameters were inferred, taking into account the "Inhalation of contaminant" as exposure pathway in a "residential scenario". An example of a residential scenario could consist of inhalation exposure for up to 24 hours per day, up to 350 days per year for 6 to 24 years for child and adult respectively (USEPA 2009 - Part F).

The methodology procedure for the estimation of inhalation exposure was detailed in USEPA 2009 Part F Document.

Concerning the exposure parameters related to EFg value (now daily Exposure Time= ET), the USEPA 1991 Document indicates " 24 hours, the whole day" as "resident air exposure time" and then setting in according with time spent in a specific site. Actually, in the light of your suggestions, an ED value of 6 
hours seems rather high, thus as recommended by USEPA table of time spent outdoor (mean of 289 $\mathrm{min} /$ day for maximum age range considered) and according with lower limit indicated by you (80-95\% time spent indoor), we have correct it considering 5 hours as ED value. Calculation were again performed.

- 3. Finally, authors estimate risks due to exposure to metals in PM10 in ambient air. Assumingly these are inhalation risks but the THQ and CR calculation were done using reference dose (RfD) and cancer slope (CSF) for ingestion exposure. It is not clear to me why authors did not use the USEPA methodology for inhalation exposure (Chronic Inhalation Reference Concentration RfC ( $\mathrm{mg} / \mathrm{m3})$; Chronic Inhalation Unit Risk IUR ( $\mu \mathrm{g} / \mathrm{m3})-1$ (THQ, TR). The available information can be found here: (section 4.9.1-2): http://www.epa.gov/reg3hwmd/risk/human/rb-concentration table/usersquide.htm I think that their approach needs major revisions.

Thank you for the observation. As told before (your comment $n^{\circ} 2$ ), it was a spelling mistake. In the light of your suggestions, we have checked the USEPA methodology and new calculations were performed, taking into account the most recent USEPA update (November 2013) concerning RfC and IUR values, as added in the manuscript (page 9, lines 231-242).

- 4. Table 2: Reference [17]? Missing in the list of references (ISS-ISPESL).It is difficult to find/confirm data in Italian database. Furthermore, once USEPA approach is used, RfD and CSF referred by USEPA should be use: please consult the following link for Regional Screening Level (RSL) Summary Table: http://www.epa.gov/reg3hwmd/risk/human/rbconcentration table/Generic Tables/docs/master sl table run NOV2013.pdf

"Table 2" is now entitled "Table 1"; here the updated values from USEPA 2013 updated Table were reported as you suggested, and new specifications about it were provided in the text in the Material and Methods Section.

\section{RESULT}

- Lines 222-233 (section 3.1) should be enhanced: authors compared average metals concentrations of 3 days measurements with annual targets. In addition, according to the statement in lines 140-142 the measurements were performed during winter season with greater exposure i.e. metals levels in ambient air; the EU target values might not be exceeded during other seasons.

Thank you, we added a sentence at lines 276-277 to enforce your observation.

- Lines 264-265 This statement is obvious once PM10 contains both fractions. Remove/change. Lines 265-266: Considering different deposition places of both fractions the statement "indeed total PM10......" is not correct. I am not sure what authors want to state. Furthermore according to Figure 1 most of the some metals (are predominantly (up to 70\%) found in fine fraction.

Ok, we removed the sentence about the PM10 inhalation and we improved the text (lines 300-303). 


\section{DISCUSSION}

- Line 288-300 this section should be placed in introduction

Ok, we moved the sentence in the introduction (lines 111-117).

- Line 301: Mn causes carcinogenic risks.... CR risk assessment of Mn was not performed.

Authors should add discussion on different species metals and potential impacts. Finally, I believe that changes in calculations of THQ, CR using IUR, RfC will cause major changes/alterations which should be reflected in results/discussion.

Thank you for the observation. It was a mistake we added toxic referred to $\mathrm{Mn}$ (lines 349-350). We also discussed about different species metals and potential impacts (lines 350-362). 
1 PM10 size distribution of metals and environmental-sanitary risk analysis in the city of Torino

2

3

4

5

6 Schilirò $^{\mathrm{a}^{*}}$, Giorgio Gilli ${ }^{\mathrm{a}}$

7

8

9 mail address: tiziana.schiliro@unito.it

\section{6} 7

\section{.} 9 0 1

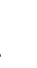
marco.casazza@unito.it, angelo.piano@unito.it ${ }^{c}$ Department of Physic Chemistry, University of Torino, Via P. Giuria, 7 - 10125, Torino, Italy; mery.malandrino@unito.it, valter.maurino@unito.it

${ }^{a}$ Department of Public Health and Pediatrics, University of Torino, Piazza Polonia, 94 - 10126, Torino, Italy; valeria.romanazzi@unito.it, tiziana.schiliro@unito.it, giorgio.gilli@unito.it

${ }^{\mathrm{b}}$ Department of Physic “A. Avogadro”, University of Torino, Via P. Giuria, 7 - 10126, Torino, Italy;

merymalandrino@unitoit, valtermaurino@unitoit

*CORRESPONDING AUTHOR: Tel: +390116705820; fax:+390116705874, Department of Public Health and Pediatrics, University of Torino, Piazza Polonia, 94 - 10126, Torino, Italy, e25 6 


\section{ABSTRACT}

The mechanisms responsible for negative biological effects due to airborne particulate matter (PM) exposure are still being studied, however the interactions between metals and biologic systems seem to be of primary importance. The aim of the study was to estimate a healthy risk linked to exposure to airborne PM10 metals by means of an environmental-sanitary risk assessment. Metals PM10 size distribution analysis was carried out in a central site of Torino city-Italy, then the Total Hazard Quotient (THQ) and the Cancer Risk (CR) were applied, according to standard EPA methods.

All sampled metals were present on the different PM10 fractions, however some metals were distributed in some specific fractions: ANOVA test shows $\mathrm{Cr}, \mathrm{Cu}, \mathrm{Mo}$ and $\mathrm{Pb}$ as differently distributed among the eight fractions, rising the hypothesis of potential effects in specific tracts of respiratory system. Regarding the risk assessment, in general the CR was higher for an adult than for a child, conversely the THQ resulted higher for a child.

While the concentrations of all the sampled metals appeared to be under control, their presence in the different PM10 fractions and their THQ and CR provided indications related to the body districts potentially in contact with these substances. (1) 3 4 5 6 7 8 9 0 1 2 


\section{HIGHLIGHTS:}

54 - Traces metals are differently distributed among the PM10 fractions

55

56

57

58

59

60

61

62

63

64

65

66

67

68

69

70

71

72

73

74

75

76

77

78

79

- $\quad$ The metals distribution in PM fractions can be useful for sanitary risk assessment

- Sanitary risk assessment shows potential risks for exposure to some metals on PM

\section{KEY WORDS:}

PM10, metals, health-sanitary risk analysis

0

\section{CONFLICT OF INTEREST:}

2 Authors declare no conflict of interest.

3

\section{ACKNOWLEDGEMENTS:}

5 This study was financed by a University of Torino Local Research grant.

6

7

68

69

70

71

2

73

74

5

6

\section{7} 8 79 


\section{INTRODUCTION}

Airborne particulate matter (PM) can be classified as PM10 (particles with an aerodynamic diameter $\emptyset$ less than $10 \mu \mathrm{m}), \operatorname{PM} 2.5(\varnothing<2.5 \mu \mathrm{m})$ and PM1 $(\varnothing<1 \mu \mathrm{m})$. The coarse fraction (PM10, 2.5-10 $\mu \mathrm{m})$ has predominantly natural sources (geological material, such as fugitive and resuspended dust, and biological material, such as pollen and endotoxins), and its composition changes depending on the geology of the site considered. The fine fractions (PM2.5 and PM1) are dominated by combustion derived particles, consisting mainly of organic and inorganic elements adsorbed onto the surface of a carbonaceous core (Bruggemann et al., 2009) and secondary particles produced by photochemical reactions in the atmosphere (sulphates and nitrates). The carbonaceous fraction consists of aggregates of organic and inorganic carbon on which are adsorbed transition metals ( $\mathrm{Pb}, \mathrm{Cd}, \mathrm{V}, \mathrm{Ni}, \mathrm{Cu}, \mathrm{Zn}, \mathrm{Mn}, \mathrm{Fe}$ ), organic compounds and biological constituents (USEPA, 1996). Coarse particles are mainly deposited in the extrathoracic region, while some inhaled fine particles reach the alveolar region of the lung (Kawanaka et al., 2011). The PM coarse fraction has been associated with pro-inflammatory and cytotoxic effects (Gualtieri et al., 2010; Hetland et al., 2004; Schiliro' et al., 2010); the PM fine fractions have been associated mainly to a higher genotoxic potential (Billet et al., 2008; Bonetta et al., 2009; de Kok et al., 2005; Traversi et al., 2009).

The mechanisms responsible for these biological effects have been continuously undergone review, and many questions still remain around some relevant aspects, for example specific dimensional fraction, number or mass of the particles, chemical components, among which metal compounds are relevant species. The metals and their compounds are found distributed among various dimensional fractions of the PM in the atmosphere. The transport and distribution of aerosol particles strictly depends on their size, besides on the weather conditions (Poschl, 2005; Stone et al., 2009): for this reason concentration, composition and size distribution of atmospheric metals particles are temporally and spatially highly variable. On the other hand the size particles depends mainly from emission sources: typically those emitted from anthropogenic sources are smaller than those emitted 
from natural sources (Harrison et al., 2012). Metals are associated both to the coarse and to the fine fractions, in which they occur generally as different chemical compounds and in different oxidation state. On the basis of existing scientific evidence, many metals (often depending on their oxidation state) may have a direct or indirect active role in the mechanisms of PM biological action (Ziemacki et al., 2003).

Many metals are physiologically present in the human body as metal-enzymes or metal-protein such as iron (catalase and heme), zinc (RNA polymerase, carbonic anhydrase, $\mathrm{Cu}-\mathrm{Zn}$ superoxide dismutase, angiotensin I converting enzyme), copper (superoxide dismutase, cytochrome oxidase, dopamine hydroxylase, and several other oxidases that reduce molecular oxygen) and manganese (mitocondrial Mn superoxide dismutase, glutamine synthetase, arginase, and activates several hydrolases, transferases and carboxylases) (Davis and Greger, 1992; Fraga, 2005; Hamilton et al., 2000; Kanumakala et al., 2002). Some chemical-physical factors such as hydrosolubility, dimensional distribution and the incorporation into aerosol particles, could influence the bioavailability of metals in PM. Since toxic and carcinogenic properties are well known for many metals, research on deposition of particle-bound mutagens in the atmosphere - first of all at respiratory level - is demanded for assessment of the influence of PM on human health. Thus deeper investigations on atmospheric concentrations, chemical characteristics and physical-chemical properties of the various metals present in the atmosphere are generally more limited respect to the past. This is also true for the potential risks to which humans are undergone in relation to their chronic presence in atmosphere. As metals represent hazard to human health, careful monitoring should be considered. Furthermore the investigation of the health risks associated with airborne metals may provide useful information regarding environmental risks of outdoor environments. The Directive 2008/50/EC of the European Parliament and of the Council establishes annual target values for the concentration of As $\left(6 \mathrm{ng} \mathrm{m}^{-3}\right), \mathrm{Cd}\left(5 \mathrm{ng} \mathrm{m}^{-3}\right)$ and $\mathrm{Ni}\left(20 \mathrm{ng} \mathrm{m}^{-3}\right)$ (determined on PM10 fraction) in ambient air so as to avoid, prevent or reduce harmful effects of these substances 
on human health and the environment as a whole (Italian transposition of Directive: D.Lgs. 155, 2010).

In the international context, the procedure of environmental-sanitary risk assessment has assumed a central role in the management of contaminated environments, mainly with reference to emerging pollutants but the same procedure can be successfully applied to other fields of interest, such as surface waters, contaminated sites, foods and pharmaceuticals (Jin et al., 2012; Ruffino et al., 2013; Stasinakis et al., 2012).

In order to address these issues, after an historical data comparison considering three representative periods with changes of emission characteristic (Casazza et al., 2013), size distributions of trace metals of specific health concern in size fractionated PM10 were evaluated. Samples were collected in a urban site (traffic oriented in the urban area of Torino, a north Italian city). Finally, the environmental-sanitary risk assessment was carried out, in order to evaluate if the metals in the different PM fractions may pose a health risk to child or adult via inhalation of airborne PM.

\section{MATERIALS AND METHODS}

\subsection{PM sampling}

PM sampling was carried out in the city of Torino - Italy. The city has an area of $130,2 \mathrm{Km}^{2}$ and a population of 908.551 inhabitants. Our sampling occurred during three autumn/winter days in 2011. This choice is due to different factors. From one side, during this period the emission sources of atmospheric pollutants are more numerous and intense. In the same period some atmospheric phenomena occur, such as thermal inversions, that can lead to a greater exposure levels for the population (Cirera et al., 2009). The sampling days were chosen considering the presence of stable good weather conditions, in order to exclude any macroscopic effect due to transport and scavenging phenomena. The mean temperature and humidity during the sampling period were 15.5 ${ }^{\circ} \mathrm{C}$ and $71 \%$ respectively. PM sampling was performed using an Andersen 2000 Inc. 'Mark II' model 
8-stages cascade impactor, which allows aerosol particles subdivision with respect to different cutoff diameters: $0.54,0.88,1.60,2.70,4.00,5.85,9.00$ and $11 \mu \mathrm{m}$. The cascade impactor was connected to an Andersen 2000 Inc. model 22-000 pump, with a selected air flux of 28.3 1/min, checked through a volumetric measurer. For collecting the particle fractions, we used Whatman no. 5 cellulose acetate filters, having a diameter of $110 \mathrm{~mm}$, that were weighted, before and after the field measures, using an analytical scale having a resolution of $0.001 \mathrm{mg}$. The sampling site was located outdoors, fifteen-m high, in central zone of the city, with residential/commercial emissions, "sandwiched" between two busy streets and not far from a green area. After weighing, the filters were stored in a freezer at $-18{ }^{\circ} \mathrm{C}$ until the metal extraction process.

\subsection{Filter extraction and metals quantification}

Following the air sampling, different metals were quantified from each of the eight filters of the sampler; the quantified metals were: V, Cr, Mn, Fe, Co, Ni, Cu, Zn, As, Mo, Rh, Pd, Cd, Sn, Pt and $\mathrm{Pb}$. In particular, after the acid attack in a microwave digestor (Milestone, MLS-1200 Mega) through a mixture 1:4 of hydrogen peroxide (30\% Fluka pa) and Carlo Erba HNO3 65\% purified by sub-boiling, the quantification has been made. double focusing magnetic sector inductively coupled plasma mass spectrometer (Thermo Finnigan Element 2). Mass resolution and isotope selection were optimized for each element to ensure resolution of spectral interferences and maximize sensitivity. A minimum of triplicate $180 \mathrm{~s}$ analyses on each sample was conducted following a $60 \mathrm{~s}$ uptake and stabilization period. Between samples the nebulizer system was rinsed for 2 min with $2 \%$ sub-boiled $\mathrm{HNO}_{3}$, which eliminated carry-over and reconditioned the sampler cone. Sets of instrumental blank and calibration verification checks were run at frequent intervals during the batch sequence. The calibrations were performed with standard solutions prepared in aliquots of sample blanks. Process blanks were incorporated into the dissolution and analytical procedure to assess metal contribution from the filters, bombs, Milli-Q water and purified acids used in this 
procedure. All signals for samples were obtained after subtraction of their appropriate process blank values. The relative standard deviation for all elements in each sample was always lower than $5 \%$.

NIST SRM 1648a (Urban Particulate Matter) was used to verify that analyte concentrations were within $15 \%$ of the expected values before proceeding with sample analysis. The analytical process conditions were: (1) plasma power: $1270 \mathrm{~W}$; (2) gas flux through the nebulizer: $1.07 \mathrm{~L} \mathrm{~min}^{-1}$; (3) auxiliary gas flux: $1.1 \mathrm{~L} \mathrm{~min}^{-1}$; (4) plasma gas flux: $15 \mathrm{~L} \mathrm{~min}^{-1}$; (5) peristaltic pump speed: $7 \mathrm{rpm}$; (6) integration time: $10 \mathrm{~s}$; (7) scanning: 9 (low resolution) and 12 (medium resolution). The LODs and LOQs in the conditions reported were, respectively, under 0.01 and $0.03 \mathrm{ng} \mathrm{L}^{-1}$ for all the element quantified, which resulted in minimum detectable and quantifiable amounts referred to the volume of air sampled $\left(280 \mathrm{~m}^{3}\right)$ of 0.002 and $0.006 \mathrm{ng} \mathrm{m}^{-3}$.

\subsection{Risk analysis}

A risk assessment was carried out. The receptors were adults and children living in Torino. The sources of contamination were the different PM10 fractions, in which chemicals were considered as stratified on the 3 main pooled PM10 fractions: coarse, PM2.5 and PM1. The chemicals of concern involved in the risk assessment were $\mathrm{V}, \mathrm{Cr}, \mathrm{Mn}, \mathrm{Fe}, \mathrm{Co}, \mathrm{Ni}, \mathrm{Cu}, \mathrm{Zn}, \mathrm{As}, \mathrm{Mo}, \mathrm{Rh}, \mathrm{Pd}, \mathrm{Cd}, \mathrm{Sn}, \mathrm{Pt}, \mathrm{Pb}$. Among the possible routes, in this work, only inhalation of dusts and gases from PM was taken into account, since it is the most important exposure route to PM of health concern. In risk quantification for each receptor (child or adult), the risks due to each contaminant were divided into two categories: non-carcinogens and carcinogens.

According to standard EPA methods (USEPA, 1989; USEPA, 2009; USEPA, 2011) for noncarcinogenic chemicals, the risk target hazard quotient (THQ) (dimensionless) was calculated as in the following equation:

$$
\text { THQ }=\frac{\text { ADI }}{\text { RfD } i}
$$


where ADI, average daily intake ( $\mathrm{mg} / \mathrm{kg} / \mathrm{day})$, is the estimated dose the receptor is exposed to from an exposure route; $\mathrm{RfD} i$, reference concentration $(\mathrm{mg} / \mathrm{kg}$ day), is the dose, for a given route, that is believed to be without effect; the cumulative THQ has to be seen as the sum of the THQ calculated as in Eq. (1) for each contaminant. THQ assumes that there is a level of exposure (i.e., RfD $i$ ) below which it is unlikely for even sensitive populations to experience adverse health effects. If the exposure level (ADI) exceeds unity, there may be concern for potential noncancer effects; higher values of THQ (above unity) indicate the greater levels of concern (USEPA, 2011).

For carcinogenic chemicals, the cancer risk (CR) (dimensionless) was calculated as in the following equation:

$$
\mathrm{CR}=\mathrm{LDI} \times \mathrm{CSF}
$$

where $\mathrm{CR}$ is the probability of cancer occurring in the exposed population over a 70-year lifetime; LDI, lifetime daily intake ( $\mathrm{mg} / \mathrm{kg} / \mathrm{day})$, is the dose of contaminants the receptor is exposed to for all their life through an exposure route; CSF $\left(\mathrm{mg} \mathrm{kg}^{-1} \mathrm{day}^{-1}\right)^{-1}$ is the cancer slope factor for each exposure route derived from dose-response studies. The carcinogenic risks were assessed as the incremental probability of an individual to develop cancer, over a lifetime, as a result of exposure to that potential carcinogen (i.e., incremental or excess individual lifetime cancer risk). CR considers risk range $10^{-4}$ (risk of developing cancer over a human lifetime is 1 in 10.000) to $10^{-6}$ (risk of developing cancer over a human lifetime is 1 in 1.000.000): values below $10^{-6}$ for individual chemicals and pathways will cause negligible cancer risks but caution is recommended to ensure that the cumulative cancer risk for all potential carcinogenic contaminants does not have a cancer risk exceeding $10^{-4}$ (USEPA, 2011). However cumulative CR the maximum acceptable value is $10^{-5}$. With reference to one route of exposure, the cumulative CR is the sum of the CR calculated as in Eq. (2) for each contaminant.

Both the RfD $i$ and CSF values were derived from existent reference concentrations (RfC) and from Inhalation Unit Risk (IUR) respectively - if available (USEPA, 2013a), according to the USEPA derivation (USEPA, 2013b): 


$$
\mathrm{RfD} i=\frac{(\mathrm{RfC} \times \mathrm{IR} \times \mathrm{AR})}{(\mathrm{BW} \times 100)}
$$

$\mathrm{CSF}=\mathrm{IUR} \times(\mathrm{BW} / \mathrm{IR}) \times 1000$

where RfC is the USEPA reference concentration - if available $\left(\mathrm{mg} \mathrm{m}^{-3}\right)$, IUR is the Inhalation Unit Risk $\left(\mu \mathrm{g} \mathrm{m}^{-3}\right)^{-1}$, IR and BW are the inhalation rate and body weight of an adult $\left(20 \mathrm{~m}^{3}\right.$ day $^{-1}$ and 70 $\mathrm{kg}$, and AR is the absorption rate (100\%) (Table 1).

The daily intake, ADI for non-carcinogenics and LDI for carcinogenics, is the product of the specific exposition rate (E, daily amount, normalized on the body weight, of crumb rubber or rainwater contacted, or air breathed) and the concentration $\mathrm{C}(\mathrm{ADI}$ and $\mathrm{LDI}=\mathrm{E} \times \mathrm{C})$.

The exposition rate was calculated in the following equations:

$$
\text { (5) } \mathrm{E}(\mathrm{mg} / \mathrm{kg} \text { day })=
$$

(BW x AT)

The parameters utilized to calculate the specific exposition rates are listed in Table 2. For the noncarcinogenic ADI values, the average time was assumed to be equal to 6 years for children and 24 years for adults (equal to ED), while 70 years (lifetime) was assumed for the calculation of LDI for carcinogenic substances.

In the Risk analysis the $\mathrm{C}$ of metals on PM was considered to be equal to the concentration at the point of exposure (although this assumption is clearly not correct) and the parameter utilized for the calculation of the specific exposition rates were highly conservative.

\subsection{Statistical analysis}

One-way analysis of variance (ANOVA) were applied to evaluate any differences in the distribution of metals among both the eight singular samplers stages $(0.54,0.88,1.60,2.70,4.00,5.85,9.00$ and $11 \mu \mathrm{m})$ and the three aggregated samplers stages (coarse, PM2.5 and PM1). With this purpose the homogeneity of the variance was firstly assessed through the Levene test, thus the equal variance of 
Tukey's test was assumed for post hoc multiple comparisons. Finally, a P value of $\leq 0.05$ (twotailed) was considered to be significant for all tests. All of the statistical analyses were performed using SPSS Package, version 19.0.

\section{RESULTS}

\subsection{Air sampling and size-fractionated distribution of airborne metals}

The mean of PM10 and PM2.5 were $98 \pm 1 \mu \mathrm{g} \mathrm{m}{ }^{-3}$ and $83 \pm 1 \mu \mathrm{g} \mathrm{m}^{-3}$ respectively. These values were high and about twice taking into account the quality target (European Directive 2008/50/EC) of a daily value for PM10 of $50 \mu \mathrm{g} \mathrm{m}^{-3}$. The PM2.5/PM10 ratio ranged from $75 \%$ to $81 \%$. Referring to the annual limits of metals set by the European Directive 2008/50/EC, these are observed excluding for $\mathrm{Cd}$ for which our measurements exceed the target value of $5 \mathrm{ng} \mathrm{m}^{-3}$, being more than one order of magnitude higher than the limit (Table 3), even if our sampling reflects only a "spot" situation (daily) and the European limits refer to the yearly average. With reference to environmental monitoring at local and national level by ARPA - Piedmont competence (Agenzia Regionale per la Protezione dell'Ambiente - Piemonte), 2011 was the warmest year observed in Piedmont in the last 50 years, and concerning the precipitations an abnormal lack of rains occurred during the generally wettest months (including October). This is in addition to the conditions of atmospheric instability particularly intense in winter months, resulted in an accumulation of pollutants, especially powders and other chemical compounds, including metals. Thereafter it should be noted that in other years or seasons the EU target values might not be exceeded. The metals concentrations in the airborne particulate were below the limits set by the European Directive 2008/50/EC, due to the significant reduced presence on the surrounding territory of mining and metallurgy, as well as the ongoing disposal of large coal-fired power plants and fuel oil, which are the main anthropogenic sources of heavy metals, such as $\mathrm{As}$ and $\mathrm{Pb}$. 
Although the global situation of the air seems to be adequately under control, a different meaning to the fractionate-size sampler is given. In fact, the health significance associated with an exposure through the component fractions forming the PM10 (fine and coarse fractions), determined the need to measure the presence of metals in these fractions particle size collected at the same time, but separately, since they have different capacity of deposition in the various regions of the respiratory tract, expressing a different and specific biological action.

All sampled metals are present and variously distributed on all the eight sampler stages, however some metals are stratified in specific sampler stages: ANOVA test shows $\mathrm{Cr}, \mathrm{Cu}, \mathrm{Mo}$ and $\mathrm{Pb}$ as statistically and differently distributed among the eight sampler stages; in particular $\mathrm{Cr}$ is preferentially accumulated on the finer filter $0.54 \mu \mathrm{m}, \mathrm{Cu}$ and Mo are localized on $2.70 \mu \mathrm{m}$ filter, and finally $\mathrm{Pb}$ is accumulated on the $11 \mu \mathrm{m}$ filter (Table 3). Metals contributions were then merge in accordance with the dimensional classification of coarse, PM2.5 and PM1 (Figure 1). In this case the ANOVA test confirmed a statistically significant dimensional-dependent distribution of the same metals previously identified, also adding $\mathrm{Ni}$, $\mathrm{As}$ and $\mathrm{Pt}$; in particular $\mathrm{As}, \mathrm{Ni}, \mathrm{Mo}$ and $\mathrm{Pb}$ are preferentially accumulated on the coarse fraction, $\mathrm{Cu}$ on PM 2.5 and finally $\mathrm{Pt}$ and $\mathrm{Cr}$ on PM1. Published information about the size distribution of metals in urban atmosphere are not so extended; although relatively high proportions of pollutants including transition metals are regularly found in ultrafine PM (Sioutas et al., 2005). Considering their small size, ultrafine particles (and all that can be conveyed by them) can also readily traverse biological membranes, facilitating systemic distribution in the body and eventually revealing multiple local or systemic effects.

\subsection{Risk analysis}

The cumulative risk values from non-carcinogenic substances, THQ, calculated as in Eq. (1) for each metals, for each PM principal fraction and for each receptors (adult and child) are shown in Figures 2; these values ranged from $4.96 \times 10^{-4}$ and 1.69 for adult while from $1.80 \times 10^{-3}$ and 6.13 for child. The cumulative risk values from carcinogenic substances, CR, calculated as in Eq. (2), for 
each metals, for each PM principal fraction and for each receptors (adult and child) are shown in

Figures 3; these values ranged from $3.71 \times 10^{-8}$ and $1.04 \times 10^{-5}$ for adult while from $5.84 \times 10^{-8}$ and

$9.46 \times 10^{-6}$ for child. The non-carcinogenic risk was higher for children than for adults, in line with the fact that children are more sensitive to non-carcinogenic substances than adults (Figure 2) and the CR were comparable - in terms of order of magnitude - for adult and child. The highest THQ values for both adult and child were reported for $\mathrm{Mn}$ and $\mathrm{Cd}$, in particular the coarse fraction was the more dangerous for Mn and the PM2.5 fraction for Cd.

Regarding the CR the highest value for both adult and child was reported for Cd without significant differences in PM fractions; the coarse fraction was the more dangerous for Co and As. non-carcinogenic).

The results of the risk analysis showed that for the examined metals, the CR proved to be lower than $10^{-6}$ and the non-carcinogenic risk, THQ, lower than 1, in line with European guidelines with the exception of $\mathrm{Cd}$, for which the total PM10 THQ were 1.69 and 6.13 while total PM10 CR were $1.04 \times 10^{-5}$ and $9.46 \times 10^{-6}$ for adult and child respectively), this result was clearly correlated to the high and remarkable $\mathrm{Cd}$ concentrations evaluated in this study probably due to the working activities related to the restoring of a building nearby the sampling site. We must also account the fact that exposure to metals occurs also via ingestion and dermal contact and, if these routes are considered, the estimated risks might be higher (Slezakova et al., 2013).

\section{DISCUSSION}

The composition of PM is very variable and depends on many different factors among which sources, climate and topography are only few examples. The chemical speciation of PM has been under study for many decades and the presence of heavy metals is known from past and recent literature (Chiari et al., 2006; Pey et al., 2010). Nevertheless there are few works that associate the 
PM metals distribution to health effects stratified by dimensional particles size (Slezakova et al., 2013) by means of environmental-sanitary risk assessment. By our samplings metals appear to be variously distributed among all the fractions demonstrating their background presence. While the concentrations of all the sampled metals appear to be under control, consideration should be given to the significantly different presence of certain metals in the different PM fractions, which provides an indication related to the metals ability to penetrate into the respiratory tracts. Metals found in the finer fractions are potentially able to deeply penetrate into the bloodstream through the alveoli, to be carried far from respiratory tract.

In particular our results highlight $\mathrm{Mn}$ and $\mathrm{Cd}$ as the two metals reflecting the potential toxic or carcinogenic risks for human health. $\mathrm{Mn}$ is reported to be essential for the development of the brain, being the concentrations in human brain higher in adults (approximately $0.25 \mathrm{mg} \mathrm{g}^{-1}$ wet weight) than in infants, suggesting this metal as required for brain functions (Markesbery et al., 1984; Pomier-Layrargues et al., 1995; Takeda, 2003). When this metal is abnormally concentrated in the brain, especially in the basal ganglia, this results in neurological disorders similar to Parkinson's disease (Ono et al., 1995; Takeda, 2003), and neurotoxicity. Concerning Cd, due to its extremely protracted biological half-life (approximately 20-30 years in humans), low rate of excretion from the body and storage predominantly in soft tissues (primarily, liver and kidneys), this metal has a diversity of toxic effects including nephrotoxicity, carcinogenicity, teratogenicity and endocrine and reproductive toxicities. Current evidence suggests that exposure to $\mathrm{Cd}$ induces genomic instability through complex and multifactorial mechanisms. Most important seems to be Cd interaction with DNA mismatch repair mechanism (MMR) (Giaginis et al., 2006), and induction of apoptosis (Zarros, 2008).

Even if the levels of inhalation exposure to such metals associated with the PM may be considered too low to induce phenomena of toxicity according to the classical mechanisms, their presence even in traces - could play an important role, being a chronic exposure factor, in the development of 
biological mechanisms responsible for some of the recorded health effects on the local population,

as confirmed by risk calculation.

In conclusion for all the examined metals, carcinogenic and non-carcinogenic, and for both children

and adults, the inhalation of airborne PM10 in a urban site gave risk values about one order of

magnitude lower than those indicated in guidelines with the exception of $\mathrm{Cd}$ (which reflects a

"spot" situation); in this view the hazard quotient resulted higher for a child than for an adult while

carcinogenic risk was similar. The absence of PM-metals risk in a urban site with high pollution

levels (WHO, 2011) is concordant with the good reduction trend of metals in Europe (EEA, 2013)

that however is a matter of concern for all the policies aimed at the protection of human health.

\section{REFERENCES}

Billet, S., Abbas, I., Le Goff, J., Verdin, A., Andre, V., Lafargue, P.E., Hachimi, A., Cazier, F., Sichel, F., Shirali, P., Garcon, G. 2008. Genotoxic potential of Polycyclic Aromatic Hydrocarbons-coated onto airborne Particulate Matter (PM(2.5)) in human lung epithelial a549 cells. Cancer Letters 270, 144-155.

Bonetta, S., Gianotti, V., Gosetti, F., Oddone, M., Gennaro, M.C., Carraro, E. 2009. DNA damage in A549 cells exposed to different extracts of PM(2.5) from industrial, urban and highway sites. Chemosphere 77, 1030-4.

Bruggemann, E., Gerwig, H., Gnauk, T., Muller, K., Herrmann, H. 2009. Influence of seasons, air mass origin and day of the week on size-segregated chemical composition of aerosol particles at a kerbside. Atmospheric Environment 43, 2456-2463.

Casazza, M., Gilli, G., Piano, A., Alessio, S. 2013. Thirty-years assessment of size-fractionated particle mass concentrations in a polluted urban area and its implications for the regulatory framework. Journal of Environmental Accounting and Management 1, 48-57.

Chiari, M., Del Carmine, P., Orellana, I.G., Lucarelli, F., Nava, S., Paperetti, L. 2006. Hourly elemental composition and source identification of fine and coarse PM10 in an Italian urban area stressed by many industrial activities. Nuclear Instruments \& Methods in Physics Research Section B-Beam Interactions with Materials and Atoms 249, 584-587.

Cirera, L., Rodriguez, M., Gimenez, J., Jimenez, E., Saez, M., Guillen, J.J., Medrano, J., Martinez-Victoria, M.A., Ballester, F., Moreno-Grau, S., Navarro, C. 2009. Effects of public health interventions on industrial emissions and ambient air in Cartagena, Spain. Environmental Science and Pollution Research 16, 152-161.

Davis, C.D., Greger, J.L. 1992. Longitudinal changes of manganese-dependent superoxide dismutase and other indexes of manganese and iron status in women. Am J Clin Nutr 55, 747-52.

de Kok, T.M., Hogervorst, J.G., Briede, J.J., van Herwijnen, M.H., Maas, L.M., Moonen, E.J., Driece, H.A., Kleinjans, J.C. 2005. Genotoxicity and physicochemical characteristics of traffic-related ambient particulate matter. Environmental and Molecular Mutagenesis 46, 71-80.

EEA, E.E.A.-. 2013. Air Quality in Europe - $n^{\circ} 9 / 2013$ Report. Available at: http://www.google.it/url?sa=t\&rct=j\&q=\&esrc=s\&source=web\&cd=1\&ved=0CDQQFjAA\&url=http\% 3A\%2F\%2Fwww.eea.europa.eu\%2Fpublications\%2Fair-quality-in-europe2013\%2Fdownload\&ei=TG2cUt-rB8e2yAPSm4HAAw\&usg=AFQjCNH59uqYyNy0j63Aa18sLXTB4NOdw\&sig2=zGUyRO8NpUPUKW7T-FQuqQ\&bvm=bv.57155469,d.bGQ. 
Fraga, C.G. 2005. Relevance, essentiality and toxicity of trace elements in human health. Mol Aspects Med 26, 235-44.

Giaginis, C., Gatzidou, E., Theocharis, S. 2006. DNA repair systems as targets of cadmium toxicity. Toxicol Appl Pharmacol 213, 282-90.

Gualtieri, M., Ovrevik, J., Holme, J.A., Perrone, M.G., Bolzacchini, E., Schwarze, P.E., Camatini, M. 2010. Differences in cytotoxicity versus pro-inflammatory potency of different PM fractions in human epithelial lung cells. Toxicology in Vitro 24, 29-39.

Hamilton, I.M., Gilmore, W.S., Strain, J.J. 2000. Marginal copper deficiency and atherosclerosis. Biol Trace Elem Res 78, 179-89.

Harrison, R.M., Jones, A.M., Gietl, J., Yin, J., Green, D.C. 2012. Estimation of the contributions of brake dust, tire wear, and resuspension to nonexhaust traffic particles derived from atmospheric measurements. Environ Sci Technol 46, 6523-9.

Hetland, R.B., Cassee, F.R., Refsnes, M., Schwarze, P.E., Lag, M., Boere, A.J., Dybing, E. 2004. Release of inflammatory cytokines, cell toxicity and apoptosis in epithelial lung cells after exposure to ambient air particles of different size fractions. Toxicol In Vitro 18, 203-12.

Jin, X.W., Gao, J.J., Zha, J.M., Xu, Y.P., Wang, Z.J., Giesy, J., Richardson, K. 2012. A tiered ecological risk assessment of three chlorophenols in Chinese surface waters. Environmental Science and Pollution Research 19, 1544-1554.

Kanumakala, S., Boneh, A., Zacharin, M. 2002. Pamidronate treatment improves bone mineral density in children with Menkes disease. J Inherit Metab Dis 25, 391-8.

Kawanaka, Y., Matsumoto, E., Sakamoto, K., Yun, S.J. 2011. Estimation of the contribution of ultrafine particles to lung deposition of particle-bound mutagens in the atmosphere. Sci Total Environ 409, 1033-8.

Markesbery, W.R., Ehmann, W.D., Alauddin, M., Hossain, T.I. 1984. Brain trace element concentrations in aging. Neurobiol Aging 5, 19-28.

Ono, J., Harada, K., Kodaka, R., Sakurai, K., Tajiri, H., Takagi, Y., Nagai, T., Harada, T., Nihei, A., Okada, A., et al. 1995. Manganese deposition in the brain during long-term total parenteral nutrition. JPEN J Parenter Enteral Nutr 19, 310-2.

Pey, J., Querol, X., Alastuey, A. 2010. Discriminating the regional and urban contributions in the NorthWestern Mediterranean: PM levels and composition. Atmospheric Environment 44, 1587-1596.

Pomier-Layrargues, G., Spahr, L., Butterworth, R.F. 1995. Increased manganese concentrations in pallidum of cirrhotic patients. Lancet 345, 735.

Poschl, U. 2005. Atmospheric aerosols: Composition, transformation, climate and health effects. Angewandte Chemie-International Edition 44, 7520-7540.

Ruffino, B., Fiore, S., Zanetti, M.C. 2013. Environmental-sanitary risk analysis procedure applied to artificial turf sports fields. Environmental Science and Pollution Research 20, 4980-4992.

Schiliro', T., Alessandria, L., Degan, R., Traversi, D., Gilli, G. 2010. Chemical characterisation and cytotoxic effects in A549 cells of urban-air PM10 collected in Torino, Italy. Environmental Toxicology and Pharmacology 29, 150-157.

Sioutas, C., Delfino, R.J., Singh, M. 2005. Exposure assessment for atmospheric ultrafine particles (UFPs) and implications in epidemiologic research. Environ Health Perspect 113, 947-55.

Slezakova, K., Morais, S., Pereira, M.D. 2013. Trace metals in size-fractionated particulate matter in a Portuguese hospital: exposure risks assessment and comparisons with other countries. Environ Sci Pollut Res Int.

Stasinakis, A.S., Mermigka, S., Samaras, V.G., Farmaki, E., Thomaidis, N.S. 2012. Occurrence of endocrine disrupters and selected pharmaceuticals in Aisonas River (Greece) and environmental risk assessment using hazard indexes. Environmental Science and Pollution Research 19, 1574-1583.

Stone, E.A., Zhou, J.B., Snyder, D.C., Rutter, A.P., Mieritz, M., Schauer, J.J. 2009. A Comparison of Summertime Secondary Organic Aerosol Source Contributions at Contrasting Urban Locations. Environmental Science \& Technology 43, 3448-3454.

Takeda, A. 2003. Manganese action in brain function. Brain Res Brain Res Rev 41, 79-87. 
Traversi, D., Degan, R., De Marco, R., Gilli, G., Pignata, C., Villani, S., Bono, R. 2009. Mutagenic properties of PM2.5 urban pollution in the Northern Italy: The nitro-compounds contribution. Environment International 35, 905-910.

USEPA, E.P.A.-. 1989. Risk Assessment Guidance for Superfund Volume I Human Health Evaluation Manual (Part A). Available at: http://www.epa.gov/oswer/riskassessment/ragsa/.

USEPA, E.P.A.-. 1996. Air Quality Criteria for Particulate Matter. Available at: http://www.google.it/url?sa=t\&rct=j\&q=\&esrc=s\&source=web\&cd=3\&ved=0CEsQFjAC\&url=http\%3 A\%2F\%2Fwww.epa.gov\%2Fncea\%2Fpdfs\%2Fpartmatt\%2FVOL I AQCD PM 2nd Review Draft.pdf \&ei=8mycUq8tq4LMA 7CgqgK\&usg=AFQjCNFuWVx zwMgp0i3wGsBNvpMoxjN8g\&sig2=gFzidEhOF 3 fP-F-U-v5Cw\&bvm=bv.57155469,d.bGQ.

USEPA, E.P.A.-. 2009. Risk Assessment Guidance for Superfund - Volume I: Human Health Evaluation Manual (Part F, Supplemental Guidance for Inhalation Risk Assessment). Available at: $\leq$ http://www.google.it/url?sa=t\&rct=j\&q=\&esrc=s\&source=web\&cd=2\&ved=0CD8QFjAB\&url=http\% 3A\%2F\%2Fwww.epa.gov\%2Foswer\%2Friskassessment\%2Fragsf\%2Fpdf\%2Fpartf 200901 final.pdf\& ei=y7wxU6fGC6TrywPypYDAAw\&usg=AFQjCNGR2fJ1j42Iv3RAQijvUFNkBCR5ww\&sig2=ivorpol2qOb qoBAyP80FVw\&bvm=bv.63587204,d.bGQ>.

USEPA, E.P.A.-. 2011. Exposure Factors Handbook. Available at: $\leq$ http://www.google.it/url?sa=t\&rct=j\&q=\&esrc=s\&source=web\&cd=2\&ved=0CEEQFjAB\&url=http\% 3A\%2F\%2Fwww.epa.gov\%2Fncea\%2Fefh\%2Fpdfs\%2Fefhcomplete.pdf\&ei= rsxU9rMK6bqywPI7YLYBQ\&usg=AFQjCNFDth21M9fWarr9GOC3qakT7CGqhA\&si g2=x2kuV-aGBICxSXIluAhg2w\&bvm=bv.63587204,d.bGQ

USEPA, E.P.A.-. 2013a. Regional Screening Level (RSL) Summary Table (TR=1E-6, HQ=1) November 2013. Available at: http://www.epa.gov/region9/superfund/prg/.

USEPA, E.P.A.-. 2013b. Users' Guide and Background Technical Document for USEPA Region 9 - Preliminary Remediation Goals (PRG) Table. Available at: http://www.epa.gov/reg3hwmd/risk/human/rbconcentration table/usersguide.htm.

WHO, W.H.O.-. 2011. Urban Outdoor Air Pollution Database. Available at: http://www.google.it/url?sa=t\&rct=j\&q=\&esrc=s\&source=web\&cd=3\&ved=0CEkQFjAC\&url=http\%3 A\%2F\%2Fwww.cleanairchina.org\%2Fm\%2F100\%2Fair\%2Fmember\%2Floadfile.jsp\%3Fid\%3D47\&ei=I WycUuPII4riywPn44CQDg\&usg=AFQjCNFzIt9VYGnKdlsmaF5IhGSy8UIKLQ\&sig2=rFjoan1CFOATKqAw Wuz82Q\&bvm=bv.57155469,d.bGQ.

Zarros, A. 2008. Cadmium (Cd) as a carcinogenetic factor and its participation in the induction of lung cancer. Pneumon 21, 172-177.

Ziemacki, G., Cattani, G., Cusano, M.C., Stacchini, G., Marconi, A. 2003. [Occurrence of metals in various size fractions of particulate matter]. Ann Ist Super Sanita 39, 371-9. 
503 FIGURES CAPTIONS

504

505 Figure 1: Metals contribution (\%) among the 3 main fractions of PM. Asterisks (*) provide an indication of 506 statistically significant distribution ( $p<0.01$, ANOVA test).

507

508

509 Figure 2: Cumulative risk values from non-carcinogenic substances - THQ. A) shows values for adults, B)

510 shows values for children.THQ values are expressed as log-scale.

511

512

513 Figure 3: Cumulative risk values from carcinogenic substances - CR. A) shows values for adults, B) shows 514 values for children. CR values are expressed as log-scale.

515 
1 PM10 size distribution of metals and environmental-sanitary risk analysis in the city of Torino

2

3

4

5

6 Schilirò $^{\mathrm{a}^{*}}$, Giorgio Gilli ${ }^{\mathrm{a}}$

7

8

9 mail address: tiziana.schiliro@unito.it

\section{7} 8 9 0 1

2
marco.casazza@unito.it, angelo.piano@unito.it

${ }^{c}$ Department of Physic Chemistry, University of Torino, Via P. Giuria, 7 - 10125, Torino, Italy; mery.malandrino@unito.it, valter.maurino@unito.it

${ }^{a}$ Department of Public Health and Pediatrics, University of Torino, Piazza Polonia, 94 - 10126, Torino, Italy; valeria.romanazzi@unito.it, tiziana.schiliro@unito.it, giorgio.gilli@unito.it

${ }^{\mathrm{b}}$ Department of Physic “A. Avogadro”, University of Torino, Via P. Giuria, 7 - 10126, Torino, Italy;

(1)

*CORRESPONDING AUTHOR: Tel: +390116705820; fax:+390116705874, Department of Public Health and Pediatrics, University of Torino, Piazza Polonia, 94 - 10126, Torino, Italy, e5 26 


\section{ABSTRACT}

The mechanisms responsible for negative biological effects due to airborne particulate matter (PM) exposure are still being studied, however the interactions between metals and biologic systems seem to be of primary importance. The aim of the study was to estimate a healthy risk linked to exposure to airborne PM10 metals by means of an environmental-sanitary risk assessment. Metals PM10 size distribution analysis was carried out in a central site of Torino city-Italy, then the Total Hazard Quotient (THQ) and the Cancer Risk (CR) were applied, according to standard EPA methods.

All sampled metals were present on the different PM10 fractions, however some metals were distributed in some specific fractions: ANOVA test shows $\mathrm{Cr}, \mathrm{Cu}, \mathrm{Mo}$ and $\mathrm{Pb}$ as differently distributed among the eight fractions, rising the hypothesis of potential effects in specific tracts of respiratory system. Regarding the risk assessment, in general the CR was higher for an adult than for a child, conversely the THQ resulted higher for a child.

While the concentrations of all the sampled metals appeared to be under control, their presence in the different PM10 fractions and their THQ and CR provided indications related to the body districts potentially in contact with these substances.

\section{3}

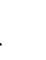
5 6 7 8 9 50 51 52 


\section{HIGHLIGHTS:}

54 - Traces metals are differently distributed among the PM10 fractions

55

56

57

58

59

60

61

62

63

64

65

66

67

68

69

70

71

72

73

74

75

76

77

78

79

- The metals distribution in PM fractions can be useful for sanitary risk assessment

- Sanitary risk assessment shows potential risks for exposure to some metals on PM

\section{KEY WORDS:}

PM10, metals, health-sanitary risk analysis

0

\section{CONFLICT OF INTEREST:}

2 Authors declare no conflict of interest.

3

\section{ACKNOWLEDGEMENTS:}

5 This study was financed by a University of Torino Local Research grant.

6

7

68

69

70

71

72

73

74

5

6

\section{7} 8 79 


\section{INTRODUCTION}

Airborne particulate matter (PM) can be classified as PM10 (particles with an aerodynamic diameter $\emptyset$ less than $10 \mu \mathrm{m}), \operatorname{PM} 2.5(\varnothing<2.5 \mu \mathrm{m})$ and PM1 $(\varnothing<1 \mu \mathrm{m})$. The coarse fraction (PM10, 2.5-10 $\mu \mathrm{m})$ has predominantly natural sources (geological material, such as fugitive and resuspended dust, and biological material, such as pollen and endotoxins), and its composition changes depending on the geology of the site considered. The fine fractions (PM2.5 and PM1) are dominated by combustion derived particles, consisting mainly of organic and inorganic elements adsorbed onto the surface of a carbonaceous core (Bruggemann et al., 2009) and secondary particles produced by photochemical reactions in the atmosphere (sulphates and nitrates). The carbonaceous fraction consists of aggregates of organic and inorganic carbon on which are adsorbed transition metals ( $\mathrm{Pb}, \mathrm{Cd}, \mathrm{V}, \mathrm{Ni}, \mathrm{Cu}, \mathrm{Zn}, \mathrm{Mn}, \mathrm{Fe}$ ), organic compounds and biological constituents (USEPA, 1996). Coarse particles are mainly deposited in the extrathoracic region, while some inhaled fine particles reach the alveolar region of the lung (Kawanaka et al., 2011). The PM coarse fraction has been associated with pro-inflammatory and cytotoxic effects (Gualtieri et al., 2010; Hetland et al., 2004; Schiliro' et al., 2010); the PM fine fractions have been associated mainly to a higher genotoxic potential (Billet et al., 2008; Bonetta et al., 2009; de Kok et al., 2005; Traversi et al., 2009).

The mechanisms responsible for these biological effects have been continuously undergone review, and many questions still remain around some relevant aspects, for example specific dimensional fraction, number or mass of the particles, chemical components, among which metal compounds are relevant species. The metals and their compounds are found distributed among various dimensional fractions of the PM in the atmosphere. The transport and distribution of aerosol particles strictly depends on their size, besides on the weather conditions (Poschl, 2005; Stone et al., 2009): for this reason concentration, composition and size distribution of atmospheric metals particles are temporally and spatially highly variable. On the other hand the size particles depends mainly from emission sources: typically those emitted from anthropogenic sources are smaller than those emitted 
from natural sources (Harrison et al., 2012). Metals are associated both to the coarse and to the fine fractions, in which they occur generally as different chemical compounds and in different oxidation state. On the basis of existing scientific evidence, many metals (often depending on their oxidation state) may have a direct or indirect active role in the mechanisms of PM biological action (Ziemacki et al., 2003).

Many metals are physiologically present in the human body as metal-enzymes or metal-protein such as iron (catalase and heme), zinc (RNA polymerase, carbonic anhydrase, $\mathrm{Cu}-\mathrm{Zn}$ superoxide dismutase, angiotensin I converting enzyme), copper (superoxide dismutase, cytochrome oxidase, dopamine hydroxylase, and several other oxidases that reduce molecular oxygen) and manganese (mitocondrial Mn superoxide dismutase, glutamine synthetase, arginase, and activates several hydrolases, transferases and carboxylases) (Davis and Greger, 1992; Fraga, 2005; Hamilton et al., 2000; Kanumakala et al., 2002). Some chemical-physical factors such as hydrosolubility, dimensional distribution and the incorporation into aerosol particles, could influence the bioavailability of metals in PM. Since toxic and carcinogenic properties are well known for many metals, research on deposition of particle-bound mutagens in the atmosphere - first of all at respiratory level - is demanded for assessment of the influence of PM on human health. Thus deeper investigations on atmospheric concentrations, chemical characteristics and physical-chemical properties of the various metals present in the atmosphere are generally more limited respect to the past. This is also true for the potential risks to which humans are undergone in relation to their chronic presence in atmosphere. As metals represent hazard to human health, careful monitoring should be considered. Furthermore the investigation of the health risks associated with airborne metals may provide useful information regarding environmental risks of outdoor environments. The Directive 2008/50/EC of the European Parliament and of the Council establishes annual target values for the concentration of As $\left(6 \mathrm{ng} \mathrm{m}^{-3}\right), \mathrm{Cd}\left(5 \mathrm{ng} \mathrm{m}^{-3}\right)$ and $\mathrm{Ni}\left(20 \mathrm{ng} \mathrm{m}^{-3}\right)$ (determined on PM10 fraction) in ambient air so as to avoid, prevent or reduce harmful effects of these substances 
on human health and the environment as a whole (Italian transposition of Directive: D.Lgs. 155, 2010).

In the international context, the procedure of environmental-sanitary risk assessment has assumed a central role in the management of contaminated environments, mainly with reference to emerging pollutants but the same procedure can be successfully applied to other fields of interest, such as surface waters, contaminated sites, foods and pharmaceuticals (Jin et al., 2012; Ruffino et al., 2013; Stasinakis et al., 2012).

In order to address these issues, after an historical data comparison considering three representative periods with changes of emission characteristic (Casazza et al., 2013), size distributions of trace metals of specific health concern in size fractionated PM10 were evaluated. Samples were collected in a urban site (traffic oriented in the urban area of Torino, a north Italian city). Finally, the environmental-sanitary risk assessment was carried out, in order to evaluate if the metals in the different PM fractions may pose a health risk to child or adult via inhalation of airborne PM.

\section{MATERIALS AND METHODS}

\subsection{PM sampling}

PM sampling was carried out in the city of Torino - Italy. The city has an area of $130,2 \mathrm{Km}^{2}$ and a population of 908.551 inhabitants. Our sampling occurred during three autumn/winter days in 2011. This choice is due to different factors. From one side, during this period the emission sources of atmospheric pollutants are more numerous and intense. In the same period some atmospheric phenomena occur, such as thermal inversions, that can lead to a greater exposure levels for the population (Cirera et al., 2009). The sampling days were chosen considering the presence of stable good weather conditions, in order to exclude any macroscopic effect due to transport and scavenging phenomena. The mean temperature and humidity during the sampling period were 15.5 ${ }^{\circ} \mathrm{C}$ and $71 \%$ respectively. PM sampling was performed using an Andersen 2000 Inc. 'Mark II' model 
8-stages cascade impactor, which allows aerosol particles subdivision with respect to different cutoff diameters: $0.54,0.88,1.60,2.70,4.00,5.85,9.00$ and $11 \mu \mathrm{m}$. The cascade impactor was connected to an Andersen 2000 Inc. model 22-000 pump, with a selected air flux of 28.3 1/min, checked through a volumetric measurer. For collecting the particle fractions, we used Whatman no. 5 cellulose acetate filters, having a diameter of $110 \mathrm{~mm}$, that were weighted, before and after the field measures, using an analytical scale having a resolution of $0.001 \mathrm{mg}$. The sampling site was located outdoors, fifteen-m high, in central zone of the city, with residential/commercial emissions, "sandwiched" between two busy streets and not far from a green area. After weighing, the filters were stored in a freezer at $-18{ }^{\circ} \mathrm{C}$ until the metal extraction process.

\subsection{Filter extraction and metals quantification}

Following the air sampling, different metals were quantified from each of the eight filters of the sampler; the quantified metals were: V, Cr, Mn, Fe, Co, Ni, Cu, Zn, As, Mo, Rh, Pd, Cd, Sn, Pt and $\mathrm{Pb}$. In particular, after the acid attack in a microwave digestor (Milestone, MLS-1200 Mega) through a mixture 1:4 of hydrogen peroxide (30\% Fluka pa) and Carlo Erba HNO3 65\% purified by sub-boiling, the quantification has been made. double focusing magnetic sector inductively coupled plasma mass spectrometer (Thermo Finnigan Element 2). Mass resolution and isotope selection were optimized for each element to ensure resolution of spectral interferences and maximize sensitivity. A minimum of triplicate $180 \mathrm{~s}$ analyses on each sample was conducted following a $60 \mathrm{~s}$ uptake and stabilization period. Between samples the nebulizer system was rinsed for 2 min with 2\% sub-boiled $\mathrm{HNO}_{3}$, which eliminated carry-over and reconditioned the sampler cone. Sets of instrumental blank and calibration verification checks were run at frequent intervals during the batch sequence. The calibrations were performed with standard solutions prepared in aliquots of sample blanks. Process blanks were incorporated into the dissolution and analytical procedure to assess metal contribution from the filters, bombs, Milli-Q water and purified acids used in this 
procedure. All signals for samples were obtained after subtraction of their appropriate process blank values. The relative standard deviation for all elements in each sample was always lower than $5 \%$. NIST SRM 1648a (Urban Particulate Matter) was used to verify that analyte concentrations were within $15 \%$ of the expected values before proceeding with sample analysis. The analytical process conditions were: (1) plasma power: $1270 \mathrm{~W}$; (2) gas flux through the nebulizer: $1.07 \mathrm{~L} \mathrm{~min}^{-1}$; (3) auxiliary gas flux: $1.1 \mathrm{~L} \mathrm{~min}^{-1}$; (4) plasma gas flux: $15 \mathrm{~L} \mathrm{~min}^{-1}$; (5) peristaltic pump speed: $7 \mathrm{rpm}$; (6) integration time: $10 \mathrm{~s}$; (7) scanning: 9 (low resolution) and 12 (medium resolution). The LODs and LOQs in the conditions reported were, respectively, under 0.01 and $0.03 \mathrm{ng} \mathrm{L}^{-1}$ for all the element quantified, which resulted in minimum detectable and quantifiable amounts referred to the volume of air sampled $\left(280 \mathrm{~m}^{3}\right)$ of 0.002 and $0.006 \mathrm{ng} \mathrm{m}^{-3}$.

\subsection{Risk analysis}

A risk assessment was carried out. The receptors were adults and children living in Torino. The sources of contamination were the different PM10 fractions, in which chemicals were considered as stratified on the 3 main pooled PM10 fractions: coarse, PM2.5 and PM1. The chemicals of concern involved in the risk assessment were $\mathrm{V}, \mathrm{Cr}, \mathrm{Mn}, \mathrm{Fe}, \mathrm{Co}, \mathrm{Ni}, \mathrm{Cu}, \mathrm{Zn}, \mathrm{As}, \mathrm{Mo}, \mathrm{Rh}, \mathrm{Pd}, \mathrm{Cd}, \mathrm{Sn}, \mathrm{Pt}, \mathrm{Pb}$. Among the possible routes, in this work, only inhalation of dusts and gases from PM was taken into account, since it is the most important exposure route to PM of health concern. In risk quantification for each receptor (child or adult), the risks due to each contaminant were divided into two categories: non-carcinogens and carcinogens.

According to standard EPA methods (USEPA, 1989; USEPA, 2009; USEPA, 2011) for noncarcinogenic chemicals, the risk target hazard quotient (THQ) (dimensionless) was calculated as in the following equation:

$$
\text { THQ }=\frac{\text { ADI }}{\text { RfD } i}
$$


where ADI, average daily intake ( $\mathrm{mg} / \mathrm{kg} / \mathrm{day})$, is the estimated dose the receptor is exposed to from an exposure route; $\mathrm{RfD} i$, reference concentration $(\mathrm{mg} / \mathrm{kg}$ day), is the dose, for a given route, that is believed to be without effect; the cumulative THQ has to be seen as the sum of the THQ calculated as in Eq. (1) for each contaminant. THQ assumes that there is a level of exposure (i.e., RfD $i$ ) below which it is unlikely for even sensitive populations to experience adverse health effects. If the exposure level (ADI) exceeds unity, there may be concern for potential noncancer effects; higher values of THQ (above unity) indicate the greater levels of concern (USEPA, 2011).

For carcinogenic chemicals, the cancer risk (CR) (dimensionless) was calculated as in the following equation:

$$
\mathrm{CR}=\mathrm{LDI} \times \mathrm{CSF}
$$

where $\mathrm{CR}$ is the probability of cancer occurring in the exposed population over a 70-year lifetime; LDI, lifetime daily intake ( $\mathrm{mg} / \mathrm{kg} /$ day), is the dose of contaminants the receptor is exposed to for all their life through an exposure route; $\operatorname{CSF}\left(\mathrm{mg} \mathrm{kg}^{-1} \mathrm{day}^{-1}\right)^{-1}$ is the cancer slope factor for each exposure route derived from dose-response studies. The carcinogenic risks were assessed as the incremental probability of an individual to develop cancer, over a lifetime, as a result of exposure to that potential carcinogen (i.e., incremental or excess individual lifetime cancer risk). CR considers risk range $10^{-4}$ (risk of developing cancer over a human lifetime is 1 in 10.000) to $10^{-6}$ (risk of developing cancer over a human lifetime is 1 in 1.000 .000$)$ : values below $10^{-6}$ for individual chemicals and pathways will cause negligible cancer risks but caution is recommended to ensure that the cumulative cancer risk for all potential carcinogenic contaminants does not have a cancer risk exceeding $10^{-4}$ (USEPA, 2011). However cumulative CR the maximum acceptable value is $10^{-5}$. With reference to one route of exposure, the cumulative CR is the sum of the CR calculated as in Eq. (2) for each contaminant.

Both the RfD $i$ and CSF values were derived from existent reference concentrations (RfC) and from Inhalation Unit Risk (IUR) respectively - if available (USEPA, 2013a), according to the USEPA derivation (USEPA, 2013b): 


$$
\operatorname{RfD} i=\frac{(\operatorname{RfC} \times \text { IR x AR })}{(B W \times 100)}
$$

(4)

$$
\mathrm{CSF}=\mathrm{IUR} \times(\mathrm{BW} / \mathrm{IR}) \times 1000
$$

where RfC is the USEPA reference concentration - if available $\left(\mathrm{mg} \mathrm{m}^{-3}\right)$, IUR is the Inhalation Unit Risk $\left(\mu \mathrm{g} \mathrm{m}^{-3}\right)^{-1}$, IR and BW are the inhalation rate and body weight of an adult $\left(20 \mathrm{~m}^{3}\right.$ day $^{-1}$ and 70 $\mathrm{kg}$, and $\mathrm{AR}$ is the absorption rate (100\%) (Table 1).

The daily intake, ADI for non-carcinogenics and LDI for carcinogenics, is the product of the specific exposition rate (E, daily amount, normalized on the body weight, of crumb rubber or rainwater contacted, or air breathed) and the concentration $\mathrm{C}(\mathrm{ADI}$ and $\mathrm{LDI}=\mathrm{E} \times \mathrm{C})$.

The exposition rate was calculated in the following equations:

(5) $\mathrm{E}(\mathrm{mg} / \mathrm{kg}$ day $)=$ - $(\mathrm{IR} \times \mathrm{ET} \times \mathrm{EF} \times \mathrm{ED})$

(BW x AT)

The parameters utilized to calculate the specific exposition rates are listed in Table 2. For the noncarcinogenic ADI values, the average time was assumed to be equal to 6 years for children and 24 years for adults (equal to ED), while 70 years (lifetime) was assumed for the calculation of LDI for carcinogenic substances.

In the Risk analysis the $\mathrm{C}$ of metals on PM was considered to be equal to the concentration at the point of exposure (although this assumption is clearly not correct) and the parameter utilized for the calculation of the specific exposition rates were highly conservative.

\subsection{Statistical analysis}

One-way analysis of variance (ANOVA) were applied to evaluate any differences in the distribution of metals among both the eight singular samplers stages $(0.54,0.88,1.60,2.70,4.00,5.85,9.00$ and $11 \mu \mathrm{m})$ and the three aggregated samplers stages (coarse, PM2.5 and PM1). With this purpose the homogeneity of the variance was firstly assessed through the Levene test, thus the equal variance of 
Tukey's test was assumed for post hoc multiple comparisons. Finally, a P value of $\leq 0.05$ (twotailed) was considered to be significant for all tests. All of the statistical analyses were performed using SPSS Package, version 19.0.

\section{RESULTS}

\subsection{Air sampling and size-fractionated distribution of airborne metals}

The mean of PM10 and PM2.5 were $98 \pm 1 \mu \mathrm{g} \mathrm{m}^{-3}$ and $83 \pm 1 \mu \mathrm{g} \mathrm{m}^{-3}$ respectively. These values were high and about twice taking into account the quality target (European Directive 2008/50/EC) of a daily value for PM10 of $50 \mu \mathrm{g} \mathrm{m}^{-3}$. The PM2.5/PM10 ratio ranged from $75 \%$ to $81 \%$. Referring to the annual limits of metals set by the European Directive 2008/50/EC, these are observed excluding for $\mathrm{Cd}$ for which our measurements exceed the target value of $5 \mathrm{ng} \mathrm{m}^{-3}$, being more than one order of magnitude higher than the limit (Table 3), even if our sampling reflects only a "spot" situation (daily) and the European limits refer to the yearly average. With reference to environmental monitoring at local and national level by ARPA - Piedmont competence (Agenzia Regionale per la Protezione dell'Ambiente - Piemonte), 2011 was the warmest year observed in Piedmont in the last 50 years, and concerning the precipitations an abnormal lack of rains occurred during the generally wettest months (including October). This is in addition to the conditions of atmospheric instability particularly intense in winter months, resulted in an accumulation of pollutants, especially powders and other chemical compounds, including metals. Thereafter it should be noted that in other years or seasons the EU target values might not be exceeded. The metals concentrations in the airborne particulate were below the limits set by the European Directive 2008/50/EC, due to the significant reduced presence on the surrounding territory of mining and metallurgy, as well as the ongoing disposal of large coal-fired power plants and fuel oil, which are the main anthropogenic sources of heavy metals, such as $\mathrm{As}$ and $\mathrm{Pb}$. 
Although the global situation of the air seems to be adequately under control, a different meaning to the fractionate-size sampler is given. In fact, the health significance associated with an exposure through the component fractions forming the PM10 (fine and coarse fractions), determined the need to measure the presence of metals in these fractions particle size collected at the same time, but separately, since they have different capacity of deposition in the various regions of the respiratory tract, expressing a different and specific biological action.

All sampled metals are present and variously distributed on all the eight sampler stages, however some metals are stratified in specific sampler stages: ANOVA test shows $\mathrm{Cr}, \mathrm{Cu}, \mathrm{Mo}$ and $\mathrm{Pb}$ as statistically and differently distributed among the eight sampler stages; in particular $\mathrm{Cr}$ is preferentially accumulated on the finer filter $0.54 \mu \mathrm{m}, \mathrm{Cu}$ and Mo are localized on $2.70 \mu \mathrm{m}$ filter, and finally $\mathrm{Pb}$ is accumulated on the $11 \mu \mathrm{m}$ filter (Table 3). Metals contributions were then merge in accordance with the dimensional classification of coarse, PM2.5 and PM1 (Figure 1). In this case the ANOVA test confirmed a statistically significant dimensional-dependent distribution of the same metals previously identified, also adding $\mathrm{Ni}$, $\mathrm{As}$ and $\mathrm{Pt}$; in particular $\mathrm{As}, \mathrm{Ni}, \mathrm{Mo}$ and $\mathrm{Pb}$ are preferentially accumulated on the coarse fraction, $\mathrm{Cu}$ on PM 2.5 and finally $\mathrm{Pt}$ and $\mathrm{Cr}$ on PM1. Published information about the size distribution of metals in urban atmosphere are not so extended; although relatively high proportions of pollutants including transition metals are regularly found in ultrafine PM (Sioutas et al., 2005). Considering their small size, ultrafine particles (and all that can be conveyed by them) can also readily traverse biological membranes, facilitating systemic distribution in the body and eventually revealing multiple local or systemic effects.

\subsection{Risk analysis}

The cumulative risk values from non-carcinogenic substances, THQ, calculated as in Eq. (1) for each metals, for each PM principal fraction and for each receptors (adult and child) are shown in Figures 2; these values ranged from $4.96 \times 10^{-4}$ and 1.69 for adult while from $1.80 \times 10^{-3}$ and 6.13 for child. The cumulative risk values from carcinogenic substances, CR, calculated as in Eq. (2), for 
each metals, for each PM principal fraction and for each receptors (adult and child) are shown in 316 Figures 3; these values ranged from $3.71 \times 10^{-8}$ and $1.04 \times 10^{-5}$ for adult while from $5.84 \times 10^{-8}$ and $9.46 \times 10^{-6}$ for child. The non-carcinogenic risk was higher for children than for adults, in line with the fact that children are more sensitive to non-carcinogenic substances than adults (Figure 2) and the CR were comparable - in terms of order of magnitude - for adult and child. The highest THQ values for both adult and child were reported for $\mathrm{Mn}$ and $\mathrm{Cd}$, in particular the coarse fraction was the more dangerous for Mn and the PM2.5 fraction for $\mathrm{Cd}$.

Regarding the CR the highest value for both adult and child was reported for Cd without significant differences in PM fractions; the coarse fraction was the more dangerous for Co and As. non-carcinogenic).

The results of the risk analysis showed that for the examined metals, the CR proved to be lower the exception of $\mathrm{Cd}$, for which the total PM10 THQ were 1.69 and 6.13 while total PM10 CR were $1.04 \times 10^{-5}$ and $9.46 \times 10^{-6}$ for adult and child respectively), this result was clearly correlated to the high and remarkable $\mathrm{Cd}$ concentrations evaluated in this study probably due to the working activities related to the restoring of a building nearby the sampling site. We must also account the fact that exposure to metals occurs also via ingestion and dermal contact and, if these routes are considered, the estimated risks might be higher (Slezakova et al., 2013).

\section{DISCUSSION}

The composition of PM is very variable and depends on many different factors among which sources, climate and topography are only few examples. The chemical speciation of PM has been under study for many decades and the presence of heavy metals is known from past and recent literature (Chiari et al., 2006; Pey et al., 2010). Nevertheless there are few works that associate the 
PM metals distribution to health effects stratified by dimensional particles size (Slezakova et al., 2013) by means of environmental-sanitary risk assessment. By our samplings metals appear to be variously distributed among all the fractions demonstrating their background presence. While the concentrations of all the sampled metals appear to be under control, consideration should be given to the significantly different presence of certain metals in the different PM fractions, which provides an indication related to the metals ability to penetrate into the respiratory tracts. Metals found in the finer fractions are potentially able to deeply penetrate into the bloodstream through the alveoli, to be carried far from respiratory tract.

In particular our results highlight $\mathrm{Mn}$ and $\mathrm{Cd}$ as the two metals reflecting the potential toxic or carcinogenic risks for human health. Mn is reported to be essential for the development of the brain, being the concentrations in human brain higher in adults (approximately $0.25 \mathrm{mg} \mathrm{g}^{-1}$ wet weight) than in infants, suggesting this metal as required for brain functions (Markesbery et al., 1984; Pomier-Layrargues et al., 1995; Takeda, 2003). When this metal is abnormally concentrated in the brain, especially in the basal ganglia, this results in neurological disorders similar to Parkinson's disease (Ono et al., 1995; Takeda, 2003), and neurotoxicity. Concerning Cd, due to its extremely protracted biological half-life (approximately 20-30 years in humans), low rate of excretion from the body and storage predominantly in soft tissues (primarily, liver and kidneys), this metal has a diversity of toxic effects including nephrotoxicity, carcinogenicity, teratogenicity and endocrine and reproductive toxicities. Current evidence suggests that exposure to $\mathrm{Cd}$ induces genomic instability through complex and multifactorial mechanisms. Most important seems to be $\mathrm{Cd}$ interaction with DNA mismatch repair mechanism (MMR) (Giaginis et al., 2006), and induction of apoptosis (Zarros, 2008).

Even if the levels of inhalation exposure to such metals associated with the PM may be considered too low to induce phenomena of toxicity according to the classical mechanisms, their presence even in traces - could play an important role, being a chronic exposure factor, in the development of 
biological mechanisms responsible for some of the recorded health effects on the local population,

as confirmed by risk calculation.

In conclusion for all the examined metals, carcinogenic and non-carcinogenic, and for both children

and adults, the inhalation of airborne PM10 in a urban site gave risk values about one order of

magnitude lower than those indicated in guidelines with the exception of $\mathrm{Cd}$ (which reflects a

"spot" situation); in this view the hazard quotient resulted higher for a child than for an adult while

carcinogenic risk was similar. The absence of PM-metals risk in a urban site with high pollution

levels (WHO, 2011) is concordant with the good reduction trend of metals in Europe (EEA, 2013)

that however is a matter of concern for all the policies aimed at the protection of human health.

\section{REFERENCES}

Billet, S., Abbas, I., Le Goff, J., Verdin, A., Andre, V., Lafargue, P.E., Hachimi, A., Cazier, F., Sichel, F., Shirali, P., Garcon, G. 2008. Genotoxic potential of Polycyclic Aromatic Hydrocarbons-coated onto airborne Particulate Matter (PM(2.5)) in human lung epithelial a549 cells. Cancer Letters 270, 144-155.

Bonetta, S., Gianotti, V., Gosetti, F., Oddone, M., Gennaro, M.C., Carraro, E. 2009. DNA damage in A549 cells exposed to different extracts of PM(2.5) from industrial, urban and highway sites. Chemosphere 77, 1030-4.

Bruggemann, E., Gerwig, H., Gnauk, T., Muller, K., Herrmann, H. 2009. Influence of seasons, air mass origin and day of the week on size-segregated chemical composition of aerosol particles at a kerbside. Atmospheric Environment 43, 2456-2463.

Casazza, M., Gilli, G., Piano, A., Alessio, S. 2013. Thirty-years assessment of size-fractionated particle mass concentrations in a polluted urban area and its implications for the regulatory framework. Journal of Environmental Accounting and Management 1, 48-57.

Chiari, M., Del Carmine, P., Orellana, I.G., Lucarelli, F., Nava, S., Paperetti, L. 2006. Hourly elemental composition and source identification of fine and coarse PM10 in an Italian urban area stressed by many industrial activities. Nuclear Instruments \& Methods in Physics Research Section B-Beam Interactions with Materials and Atoms 249, 584-587.

Cirera, L., Rodriguez, M., Gimenez, J., Jimenez, E., Saez, M., Guillen, J.J., Medrano, J., Martinez-Victoria, M.A., Ballester, F., Moreno-Grau, S., Navarro, C. 2009. Effects of public health interventions on industrial emissions and ambient air in Cartagena, Spain. Environmental Science and Pollution Research 16, 152-161.

Davis, C.D., Greger, J.L. 1992. Longitudinal changes of manganese-dependent superoxide dismutase and other indexes of manganese and iron status in women. Am J Clin Nutr 55, 747-52.

de Kok, T.M., Hogervorst, J.G., Briede, J.J., van Herwijnen, M.H., Maas, L.M., Moonen, E.J., Driece, H.A., Kleinjans, J.C. 2005. Genotoxicity and physicochemical characteristics of traffic-related ambient particulate matter. Environmental and Molecular Mutagenesis 46, 71-80.

EEA, E.E.A.-. 2013. Air Quality in Europe - $n^{\circ} 9 / 2013$ Report. Available at: http://www.google.it/url?sa=t\&rct=j\&q=\&esrc=s\&source=web\&cd=1\&ved=0CDQQFjAA\&url=http\% 3A\%2F\%2Fwww.eea.europa.eu\%2Fpublications\%2Fair-quality-in-europe2013\%2Fdownload\&ei=TG2cUt-rB8e2yAPSm4HAAw\&usg=AFQjCNH59uqYyNy0j63Aa18sLXTB4NOdw\&sig2=zGUyRO8NpUPUKW7T-FQuqQ\&bvm=bv.57155469,d.bGQ. 
Fraga, C.G. 2005. Relevance, essentiality and toxicity of trace elements in human health. Mol Aspects Med 26, 235-44.

Giaginis, C., Gatzidou, E., Theocharis, S. 2006. DNA repair systems as targets of cadmium toxicity. Toxicol Appl Pharmacol 213, 282-90.

Gualtieri, M., Ovrevik, J., Holme, J.A., Perrone, M.G., Bolzacchini, E., Schwarze, P.E., Camatini, M. 2010. Differences in cytotoxicity versus pro-inflammatory potency of different PM fractions in human epithelial lung cells. Toxicology in Vitro 24, 29-39.

Hamilton, I.M., Gilmore, W.S., Strain, J.J. 2000. Marginal copper deficiency and atherosclerosis. Biol Trace Elem Res 78, 179-89.

Harrison, R.M., Jones, A.M., Gietl, J., Yin, J., Green, D.C. 2012. Estimation of the contributions of brake dust, tire wear, and resuspension to nonexhaust traffic particles derived from atmospheric measurements. Environ Sci Technol 46, 6523-9.

Hetland, R.B., Cassee, F.R., Refsnes, M., Schwarze, P.E., Lag, M., Boere, A.J., Dybing, E. 2004. Release of inflammatory cytokines, cell toxicity and apoptosis in epithelial lung cells after exposure to ambient air particles of different size fractions. Toxicol In Vitro 18, 203-12.

Jin, X.W., Gao, J.J., Zha, J.M., Xu, Y.P., Wang, Z.J., Giesy, J., Richardson, K. 2012. A tiered ecological risk assessment of three chlorophenols in Chinese surface waters. Environmental Science and Pollution Research 19, 1544-1554.

Kanumakala, S., Boneh, A., Zacharin, M. 2002. Pamidronate treatment improves bone mineral density in children with Menkes disease. J Inherit Metab Dis 25, 391-8.

Kawanaka, Y., Matsumoto, E., Sakamoto, K., Yun, S.J. 2011. Estimation of the contribution of ultrafine particles to lung deposition of particle-bound mutagens in the atmosphere. Sci Total Environ 409, 1033-8.

Markesbery, W.R., Ehmann, W.D., Alauddin, M., Hossain, T.I. 1984. Brain trace element concentrations in aging. Neurobiol Aging 5, 19-28.

Ono, J., Harada, K., Kodaka, R., Sakurai, K., Tajiri, H., Takagi, Y., Nagai, T., Harada, T., Nihei, A., Okada, A., et al. 1995. Manganese deposition in the brain during long-term total parenteral nutrition. JPEN J Parenter Enteral Nutr 19, 310-2.

Pey, J., Querol, X., Alastuey, A. 2010. Discriminating the regional and urban contributions in the NorthWestern Mediterranean: PM levels and composition. Atmospheric Environment 44, 1587-1596.

Pomier-Layrargues, G., Spahr, L., Butterworth, R.F. 1995. Increased manganese concentrations in pallidum of cirrhotic patients. Lancet 345, 735.

Poschl, U. 2005. Atmospheric aerosols: Composition, transformation, climate and health effects. Angewandte Chemie-International Edition 44, 7520-7540.

Ruffino, B., Fiore, S., Zanetti, M.C. 2013. Environmental-sanitary risk analysis procedure applied to artificial turf sports fields. Environmental Science and Pollution Research 20, 4980-4992.

Schiliro', T., Alessandria, L., Degan, R., Traversi, D., Gilli, G. 2010. Chemical characterisation and cytotoxic effects in A549 cells of urban-air PM10 collected in Torino, Italy. Environmental Toxicology and Pharmacology 29, 150-157.

Sioutas, C., Delfino, R.J., Singh, M. 2005. Exposure assessment for atmospheric ultrafine particles (UFPs) and implications in epidemiologic research. Environ Health Perspect 113, 947-55.

Slezakova, K., Morais, S., Pereira, M.D. 2013. Trace metals in size-fractionated particulate matter in a Portuguese hospital: exposure risks assessment and comparisons with other countries. Environ Sci Pollut Res Int.

Stasinakis, A.S., Mermigka, S., Samaras, V.G., Farmaki, E., Thomaidis, N.S. 2012. Occurrence of endocrine disrupters and selected pharmaceuticals in Aisonas River (Greece) and environmental risk assessment using hazard indexes. Environmental Science and Pollution Research 19, 1574-1583.

Stone, E.A., Zhou, J.B., Snyder, D.C., Rutter, A.P., Mieritz, M., Schauer, J.J. 2009. A Comparison of Summertime Secondary Organic Aerosol Source Contributions at Contrasting Urban Locations. Environmental Science \& Technology 43, 3448-3454.

Takeda, A. 2003. Manganese action in brain function. Brain Res Brain Res Rev 41, 79-87. 
Traversi, D., Degan, R., De Marco, R., Gilli, G., Pignata, C., Villani, S., Bono, R. 2009. Mutagenic properties of PM2.5 urban pollution in the Northern Italy: The nitro-compounds contribution. Environment International 35, 905-910.

USEPA, E.P.A.-. 1989. Risk Assessment Guidance for Superfund Volume I Human Health Evaluation Manual (Part A). Available at: http://www.epa.gov/oswer/riskassessment/ragsa/.

USEPA, E.P.A.-. 1996. Air Quality Criteria for Particulate Matter. Available at: http://www.google.it/url?sa=t\&rct=j\&q=\&esrc=s\&source=web\&cd=3\&ved=0CEsQFjAC\&url=http\%3 A\%2F\%2Fwww.epa.gov\%2Fncea\%2Fpdfs\%2Fpartmatt\%2FVOL I AQCD PM 2nd Review Draft.pdf \&ei=8mycUq8tq4LMA 7CgqgK\&usg=AFQjCNFuWVx zwMgp0i3wGsBNvpMoxjN8g\&sig2=gFzidEhOF 3 fP-F-U-v5Cw\&bvm=bv.57155469,d.bGQ.

USEPA, E.P.A.-. 2009. Risk Assessment Guidance for Superfund - Volume I: Human Health Evaluation Manual (Part F, Supplemental Guidance for Inhalation Risk Assessment). Available at: $\leq$ http://www.google.it/url?sa=t\&rct=j\&q=\&esrc=s\&source=web\&cd=2\&ved=0CD8QFjAB\&url=http\% 3A\%2F\%2Fwww.epa.gov\%2Foswer\%2Friskassessment\%2Fragsf\%2Fpdf\%2Fpartf 200901 final.pdf\& ei=y7wxU6fGC6TrywPypYDAAw\&usg=AFQjCNGR2fJ1j42Iv3RAQijvUFNkBCR5ww\&sig2=ivorpol2qOb qoBAyP80FVw\&bvm=bv.63587204,d.bGQ>.

USEPA, E.P.A.-. 2011. Exposure Factors Handbook. Available at: $\leq$ http://www.google.it/url?sa=t\&rct=j\&q=\&esrc=s\&source=web\&cd=2\&ved=0CEEQFjAB\&url=http\% 3A\%2F\%2Fwww.epa.gov\%2Fncea\%2Fefh\%2Fpdfs\%2Fefhcomplete.pdf\&ei= rsxU9rMK6bqywPI7YLYBQ\&usg=AFQjCNFDth21M9fWarr9GOC3qakT7CGqhA\&si g2=x2kuV-aGBICxSXIluAhg2w\&bvm=bv.63587204,d.bGQ

USEPA, E.P.A.-. 2013a. Regional Screening Level (RSL) Summary Table (TR=1E-6, HQ=1) November 2013. Available at: http://www.epa.gov/region9/superfund/prg/.

USEPA, E.P.A.-. 2013b. Users' Guide and Background Technical Document for USEPA Region 9 - Preliminary Remediation Goals (PRG) Table. Available at: http://www.epa.gov/reg3hwmd/risk/human/rbconcentration table/usersguide.htm.

WHO, W.H.O.-. 2011. Urban Outdoor Air Pollution Database. Available at: http://www.google.it/url?sa=t\&rct=j\&q=\&esrc=s\&source=web\&cd=3\&ved=0CEkQFjAC\&url=http\%3 A\%2F\%2Fwww.cleanairchina.org\%2Fm\%2F100\%2Fair\%2Fmember\%2Floadfile.jsp\%3Fid\%3D47\&ei=I WycUuPII4riywPn44CQDg\&usg=AFQjCNFzIt9VYGnKdlsmaF5IhGSy8UIKLQ\&sig2=rFjoan1CFOATKqAw Wuz82Q\&bvm=bv.57155469,d.bGQ.

Zarros, A. 2008. Cadmium (Cd) as a carcinogenetic factor and its participation in the induction of lung cancer. Pneumon 21, 172-177.

Ziemacki, G., Cattani, G., Cusano, M.C., Stacchini, G., Marconi, A. 2003. [Occurrence of metals in various size fractions of particulate matter]. Ann Ist Super Sanita 39, 371-9. 
503 FIGURES CAPTIONS

504

505 Figure 1: Metals contribution (\%) among the 3 main fractions of PM. Asterisks (*) provide an indication of 506 statistically significant distribution ( $p<0.01$, ANOVA test).

507

508

509 Figure 2: Cumulative risk values from non-carcinogenic substances - THQ. A) shows values for adults, B)

510 shows values for children.THQ values are expressed as log-scale.

511

512

513 Figure 3: Cumulative risk values from carcinogenic substances - CR. A) shows values for adults, B) shows 514 values for children. CR values are expressed as log-scale.

515 


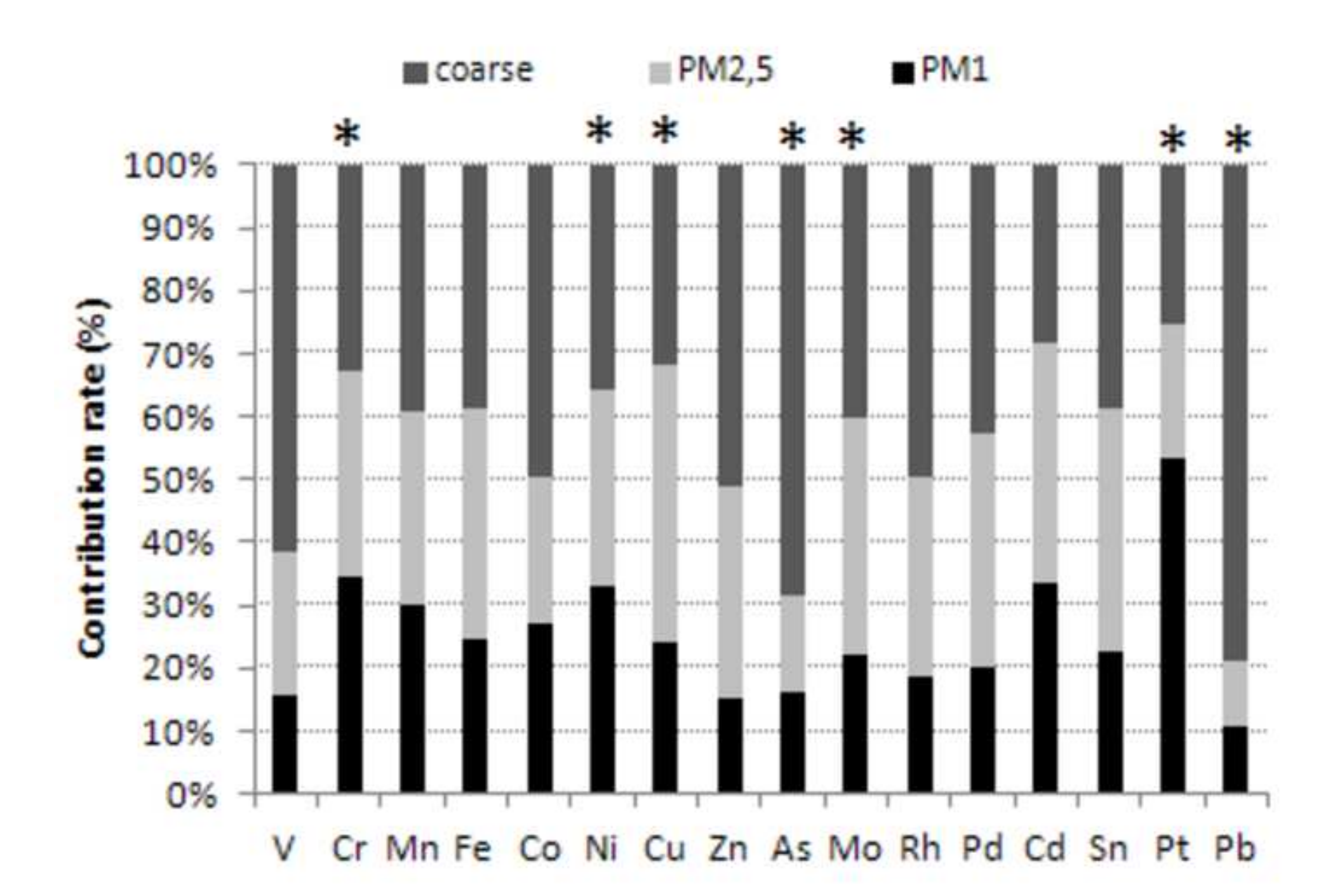

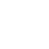
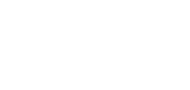

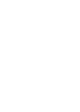
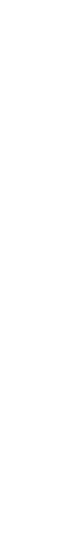
Figure 2

Click here to download high resolution image
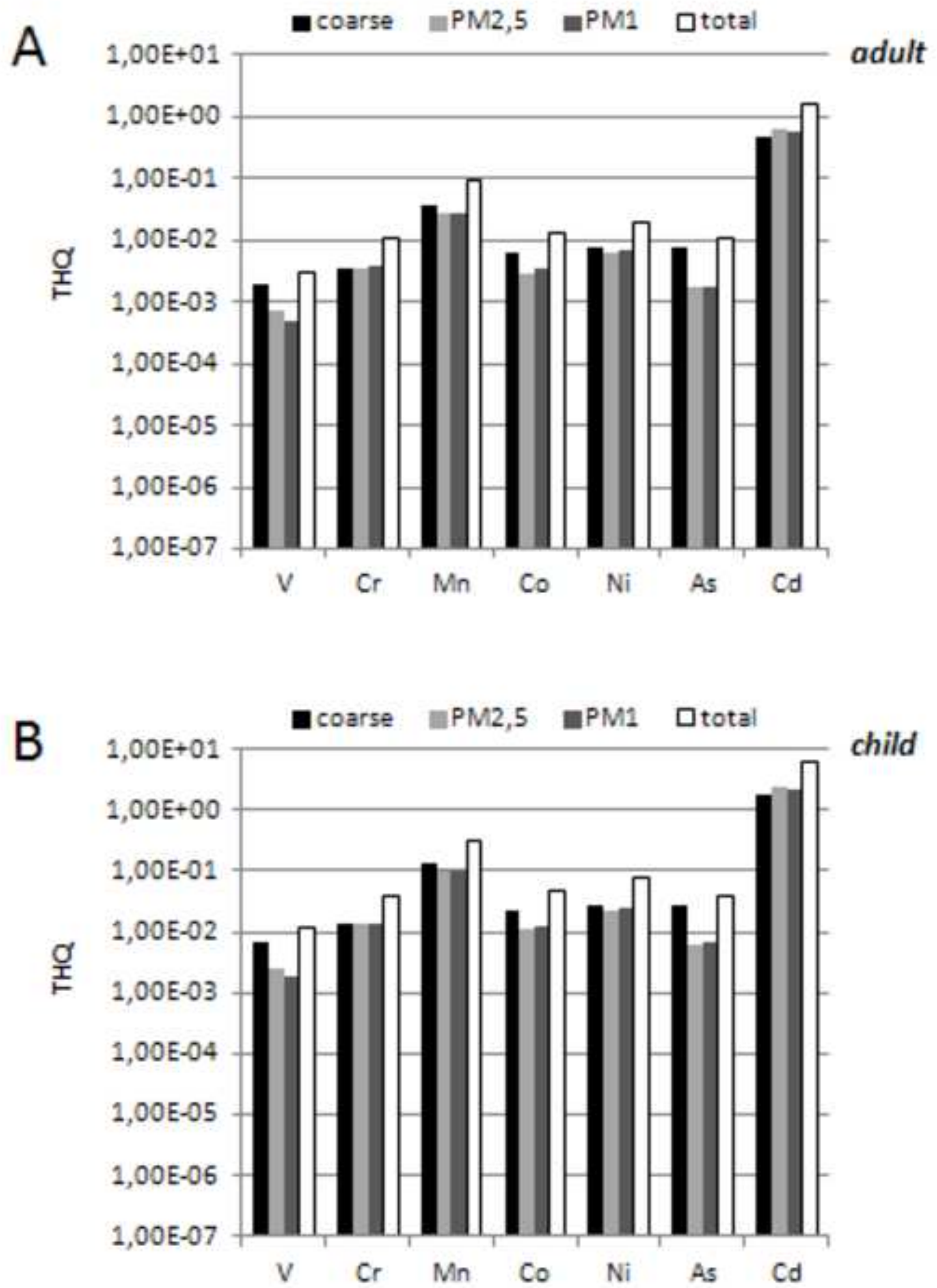
Click here to download high resolution image

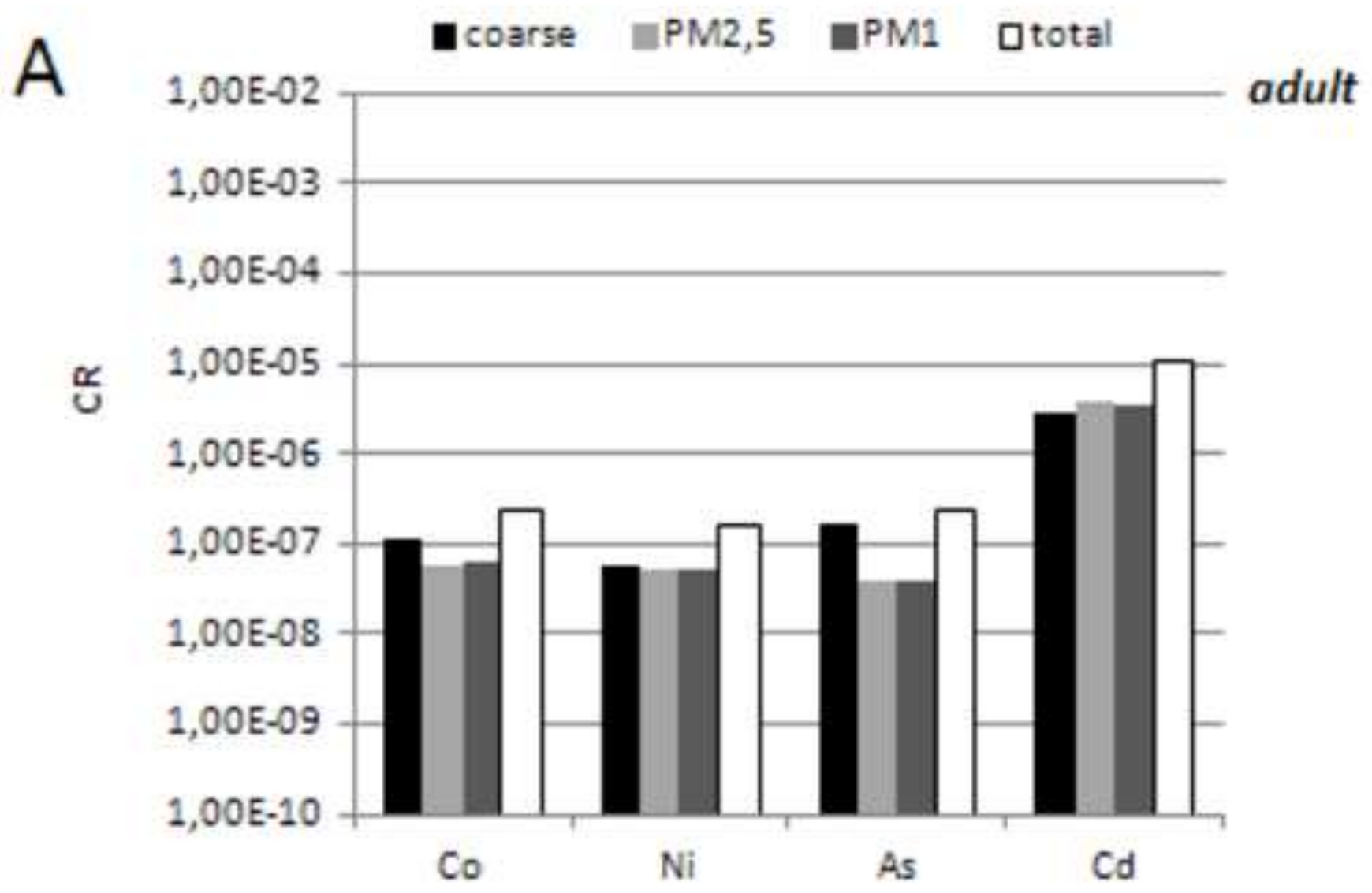

B

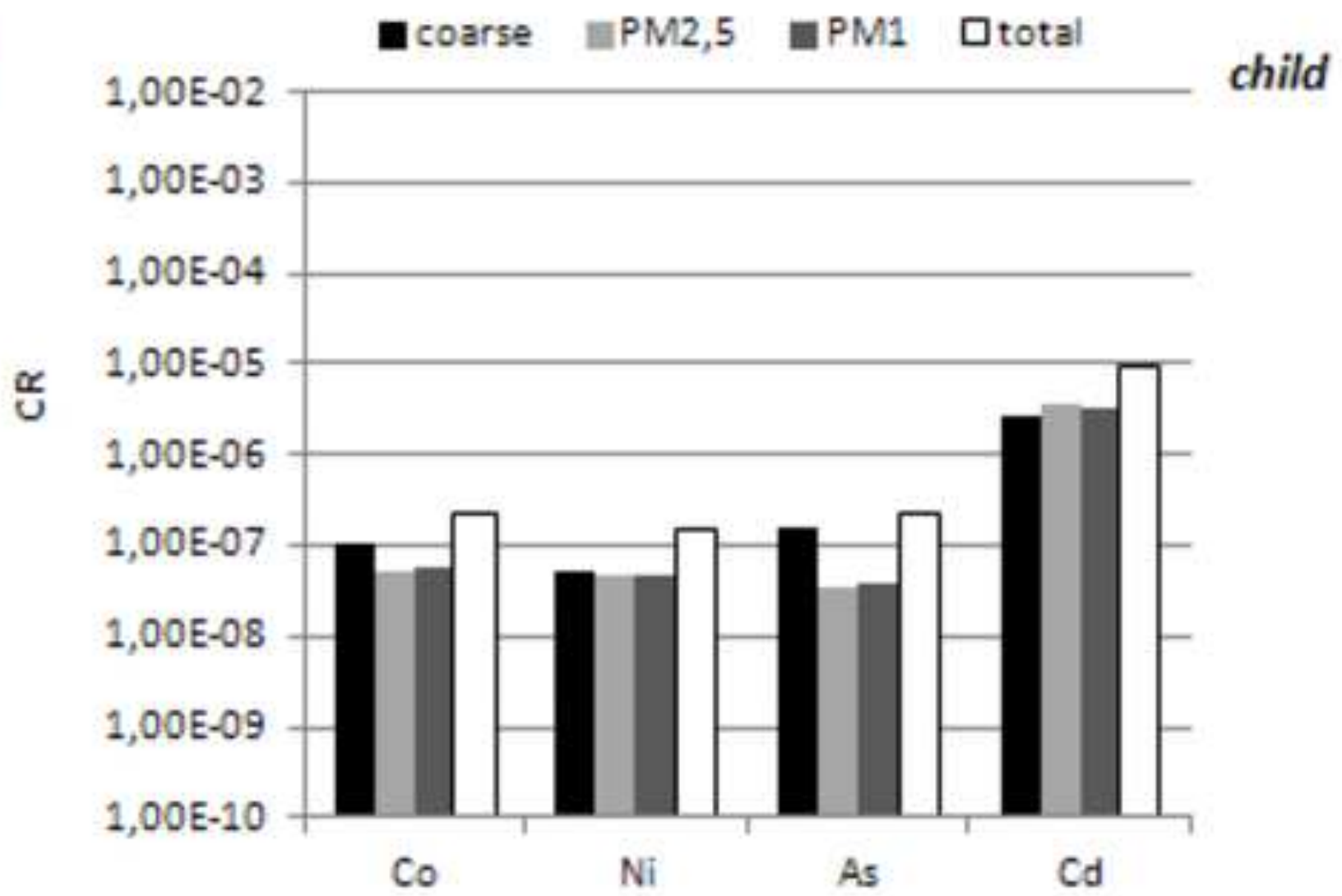


Table 1: IUR and RfC data from USEPA database (USEPA 2013a); RfDi and CSF values were derived in according with Eq. (3) and Eq. (4) respectively, as recommended by USEPA methodology (USEPA 2013b).

\begin{tabular}{c|ccccc} 
& $\mathbf{C A S}$ & $\begin{array}{c}\text { IUR } \\
{\left[\mathbf{u g} / \mathbf{m}^{3}\right]^{-1}}\end{array}$ & $\begin{array}{c}\mathbf{C S F} \\
{[\mathbf{m g} / \mathbf{K g ~ d a y}]^{-1}}\end{array}$ & $\begin{array}{c}\mathbf{R f C} \\
{\left[\mathbf{m g} / \mathbf{m}^{3}\right]}\end{array}$ & $\begin{array}{c}\mathbf{R f D i} \\
{[\mathbf{m g} / \mathbf{K g ~ d a y}]}\end{array}$ \\
\hline $\mathbf{V}$ & $7440-62-2$ & - & - & $1,00 \mathrm{E}-04$ & $2,86 \mathrm{E}-05$ \\
$\mathbf{C r}$ & $7440-47-3$ & - & - & $1,40 \mathrm{E}-04$ & $4,00 \mathrm{E}-05$ \\
$\mathbf{M n}$ & $7439-96-5$ & - & - & $5,00 \mathrm{E}-05$ & $1,43 \mathrm{E}-05$ \\
$\mathbf{F e}$ & $7439-89-6$ & - & - & - & - \\
$\mathbf{C o}$ & $7440-48-4$ & $9,00 \mathrm{E}-03$ & $3,15 \mathrm{E}+01$ & $6,00 \mathrm{E}-06$ & $1,71 \mathrm{E}-06$ \\
$\mathbf{N i}$ & $7440-02-0$ & $2,60 \mathrm{E}-04$ & $9,10 \mathrm{E}-01$ & $9,00 \mathrm{E}-05$ & $2,57 \mathrm{E}-05$ \\
$\mathbf{C u}$ & $7440-50-8$ & - & - & - & - \\
$\mathbf{Z n}$ & $7440-66-6$ & - & - & - & - \\
As & $7440-38-2$ & $4,30 \mathrm{E}-03$ & $1,51 \mathrm{E}+01$ & $1,50 \mathrm{E}-05$ & $4,29 \mathrm{E}-06$ \\
Mo & $7439-98-7$ & - & - & - & - \\
$\mathbf{R h}$ & $7440-16-6$ & - & - & - & - \\
Pd & $7440-05-3$ & - & - & - & - \\
$\mathbf{C d}$ & $7440-43-9$ & $1,80 \mathrm{E}-03$ & $6,30 \mathrm{E}+00$ & $1,00 \mathrm{E}-05$ & $2,86 \mathrm{E}-06$ \\
Sn & $7440-31-5$ & - & - & - & - \\
Pt & $7440-06-4$ & - & - & - & - \\
Pb & $7439-92-1$ & - & - & - & -
\end{tabular}


Table 2. List of parameters utilized for the calculation of the specific exposition rates. Standard default exposure factors, taking into account the "inhalation of contaminant" as exposure pathway in a "residential scenario" related to adults and children, male and female combined, for sedentary and light activity (USEPA 1989, USEPA 2009 - Part F and USEPA 2011).

\begin{tabular}{lcccc}
\hline \multicolumn{1}{c}{ parameter } & acronym & $\begin{array}{c}\text { Unit of } \\
\text { measurement }\end{array}$ & \multicolumn{2}{c}{ Numeric value } \\
adult & child \\
\hline inhalation rate & $\mathrm{IR}$ & $\mathrm{m}^{3} / \mathrm{h}$ & 0,9 & 0,7 \\
Body weight & $\mathrm{BW}$ & $\mathrm{Kg}$ & 70 & 15 \\
Exposure time & $\mathrm{ET}$ & $\mathrm{h} / \mathrm{day}$ & 5 & 5 \\
Exposure frequency & $\mathrm{EF}$ & day/year & 350 & 350 \\
Exposure duration & $\mathrm{ED}$ & years & 24 & 6 \\
Lifetime Average & $\mathrm{ATc}$ & days & 70 & 70 \\
Lifetime Average & $\mathrm{ATn}$ & days & $=\mathrm{ED}$ & $=\mathrm{ED}$ \\
\hline
\end{tabular}

$* \mathrm{ATn}=365$ days/years $\mathrm{x}$ ED; ATc $=365$ days/years $\mathrm{x} 70$ years 
Table 3: Metals abundance expressed as mean $\mathrm{ng} / \mathrm{m}^{3}$ and standard deviations (SD) among each of the size fractionated sampler stages are given. $P$ values (ANOVA) are referred to the statistically significant dimensional-dependent distribution.

\begin{tabular}{|c|c|c|c|c|c|c|c|c|c|c|}
\hline $\begin{array}{l}\text { Mean } \\
\mathrm{ng} / \mathrm{m}^{3} \\
( \pm \mathrm{SD})\end{array}$ & $\begin{array}{c}\text { FILTER } 7 \\
11,00 \mu \mathrm{m}\end{array}$ & $\begin{array}{c}\text { FILTER } 6 \\
9,00 \mu \mathrm{m}\end{array}$ & $\begin{array}{c}\text { FILTER } 5 \\
5,85 \mu \mathrm{m}\end{array}$ & $\begin{array}{c}\text { FILTER } 4 \\
\mathbf{4 , 0 0 \mu \mathrm { m }}\end{array}$ & $\begin{array}{c}\text { FILTER } 3 \\
2,70 \mu \mathrm{m}\end{array}$ & $\begin{array}{c}\text { FILTER } 2 \\
1,60 \mu \mathrm{m}\end{array}$ & $\begin{array}{c}\text { FILTER } 1 \\
\mathbf{0 , 8 8} \mu \mathrm{m}\end{array}$ & $\begin{array}{c}\text { FILTER 0 } \\
0,54 \mu \mathrm{m}\end{array}$ & TOTAL & $p$ \\
\hline $\mathbf{V}$ & $0,377( \pm 0,242)$ & $0,253( \pm 0,175)$ & $0,149( \pm 0,097)$ & $0,127( \pm 0,081)$ & $0,200( \pm 0,125)$ & $0,133( \pm 0,076)$ & $0,093( \pm 0,021)$ & $0,137( \pm 0,047)$ & $1,469( \pm 0,092)$ & - \\
\hline $\mathrm{Cr}$ & $0,413( \pm 0,251)$ & $0,477( \pm 0,197)$ & $0,573( \pm 0,110)$ & $0,883( \pm 0,101)$ & $1,247( \pm 0,137)$ & $1,100( \pm 0,217)$ & $1,150( \pm 0,495)$ & $1,350( \pm 0,882)$ & $7,193( \pm 0,368)$ & 0,049 \\
\hline Mn & $1,790( \pm 1,747)$ & $2,233( \pm 1,907)$ & $1,820( \pm 0,882)$ & $2,330( \pm 0,652)$ & $3,753( \pm 0,428)$ & $2,613( \pm 0,186)$ & $2,320( \pm 0,870)$ & $3,980( \pm 2,661)$ & $20,840( \pm 0,827)$ & - \\
\hline $\mathbf{F e}$ & $8,315( \pm 16,523)$ & $14,045( \pm 32,471)$ & $215,567( \pm 296,212)$ & $203,673( \pm 156,025)$ & $264,373( \pm 97,241)$ & $156,080( \pm 39,381)$ & $112,000( \pm 11,653)$ & $172,633( \pm 95,717)$ & $1146,687( \pm 92,934)$ & - \\
\hline Co & $0,077( \pm 0,059)$ & $0,039( \pm 0,029)$ & $0,033( \pm 0,006)$ & $0,030( \pm 0,010)$ & $0,040( \pm 0,010)$ & $0,043( \pm 0,012)$ & $0,040( \pm 0,000)$ & $0,057( \pm 0,023)$ & $0,359( \pm 0,015)$ & - \\
\hline $\mathbf{N i}$ & $1,260( \pm 0,433)$ & $0,673( \pm 0,241)$ & $0,577( \pm 0,068)$ & $0,563( \pm 0,165)$ & $0,960( \pm 0,712)$ & $1,703( \pm 0,006)$ & $1,470( \pm 0,680)$ & $1,337( \pm 0,857)$ & $8,543( \pm 0,437)$ & - \\
\hline $\mathbf{C u}$ & $0,717( \pm 0,142)$ & $0,813( \pm 0,133)$ & $1,513( \pm 0,287)$ & $2,943( \pm 0,446)$ & $4,753( \pm 1,141)$ & $3,610( \pm 0,623)$ & $2,057( \pm 0,157)$ & $2,450( \pm 1,324)$ & $18,857( \pm 1,391)$ & $<0,0001$ \\
\hline $\mathbf{Z n}$ & $41,480( \pm 43,890)$ & $22,093( \pm 17,926)$ & $7,697( \pm 2,441)$ & $27,210( \pm 17,893)$ & $41,553( \pm 29,052)$ & $22,835( \pm 21,821)$ & $16,295( \pm 43,001)$ & $13,143( \pm 5,930)$ & $192,307( \pm 12,375)$ & - \\
\hline As & $0,177( \pm 0,106)$ & $0,177( \pm 0,122)$ & $0,110( \pm 0,087)$ & $0,067( \pm 0,012)$ & $0,060( \pm 0,017)$ & $0,057( \pm 0,015)$ & $0,067( \pm 0,012)$ & $0,060( \pm 0,036)$ & $0,773( \pm 0,052)$ & - \\
\hline Mo & $0,183( \pm 0,021)$ & $0,173( \pm 0,038)$ & $0,210( \pm 0,053)$ & $0,363( \pm 0,060)$ & $0,543( \pm 0,235)$ & $0,337( \pm 0,067)$ & $0,227( \pm 0,006)$ & $0,283( \pm 0,146)$ & $2,320( \pm 0,124)$ & 0,009 \\
\hline $\mathbf{R h}$ & $0,007( \pm 0,000)$ & $0,010( \pm 0,000)$ & $0,007( \pm 0,006)$ & $0,011( \pm 0,009)$ & $0,011( \pm 0,008)$ & $0,010( \pm 0,010)$ & $0,005( \pm 0,005)$ & $0,008( \pm 0,004)$ & $0,068( \pm 0,002)$ & - \\
\hline Pd & $0,020( \pm 0,014)$ & $0,025( \pm 0,007)$ & $0,030( \pm 0,000)$ & $0,020( \pm 0,014)$ & $0,070( \pm 0,078)$ & $0,014( \pm 0,010)$ & $0,014( \pm 0,009)$ & $0,031( \pm 0,010)$ & $0,224( \pm 0,018)$ & - \\
\hline Cd & $3,113( \pm 1,497)$ & $4,847( \pm 5,078)$ & $5,900( \pm 4,345)$ & $8,127( \pm 4,963)$ & $17,123( \pm 13,136)$ & $12,837( \pm 10,260)$ & $20,997( \pm 33,050)$ & $5,363( \pm 6,235)$ & $78,307( \pm 6,493)$ & - \\
\hline Sn & $6,700( \pm 6,915)$ & $6,223( \pm 4,844)$ & $8,787( \pm 7,103)$ & $23,810( \pm 24,458)$ & $29,763( \pm 25,990)$ & $15,220( \pm 10,722)$ & $9,877( \pm 9,136)$ & $16,597( \pm 20,651)$ & $116,977( \pm 8,517)$ & - \\
\hline $\mathbf{P t}$ & $0,006( \pm 0,005)$ & $0,011( \pm 0,008)$ & $0,009( \pm 0,002)$ & $0,013( \pm 0,006)$ & $0,013( \pm 0,006)$ & $0,019( \pm 0,012)$ & $0,046( \pm 0,039)$ & $0,037( \pm 0,021)$ & $0,154( \pm 0,014)$ & - \\
\hline $\mathbf{P b}$ & $3,170( \pm 1,696)$ & $2,920( \pm 1,658)$ & $1,720( \pm 0,828)$ & $0,587( \pm 0,121)$ & $0,553( \pm 0,040)$ & $0,530( \pm 0,262)$ & $0,460( \pm 0,321)$ & $0,693( \pm 0,475)$ & $10,633( \pm 1,135)$ & 0,005 \\
\hline
\end{tabular}

